




\title{
OPERABILITY TEST REPORT for the IN SITU VAPOR SAMPLING
}

\author{
J. E. Corbett
}

Westinghouse Hanford Company, Richland, WA 99352

U.S. Department of Energy Contract DE-AC06-87RL10930

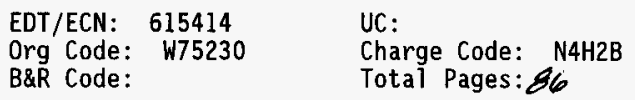

Key Words: Operability Testing, OTR, OTP, In Situ Vapor Sampling, ISVS, vapor sampling, Type IV Cart.

Abstract: This report documents the successful completion of testing for the In Situ Vapor Sampling (ISVS) system. The report includes the test procedure (WHC-SD-WM-OTP-196, Rev OA), data sheets, exception resolutions, and a test report summary. This report conforms to the guidel ines established in WHC-IP-1026, "Engineering Practice Guidelines, "Appendix L, "Operability Test Procedures and Reports."

TRADEMARK DISCLAIMER. Reference here in to any specific commercial product, process, or service by trade name, tradenark, manufacturer, or otherwise, does not necessarily constitute or imply its endorsement, recormendation, or favoring by the United States Government or any agency thereof or its contractors or subcontractors.

Printed in the United States of America. To obtain copies of this document, contact: WHC/BCS Document Control Services, P.D. Box 1970, Mailstop H6-08, Richland HA 99352, Phone (509) 372-2420; Fax (509) 376-4989.

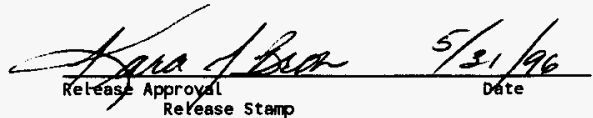

\section{Approved for Public Release}




\section{Table of Contents}

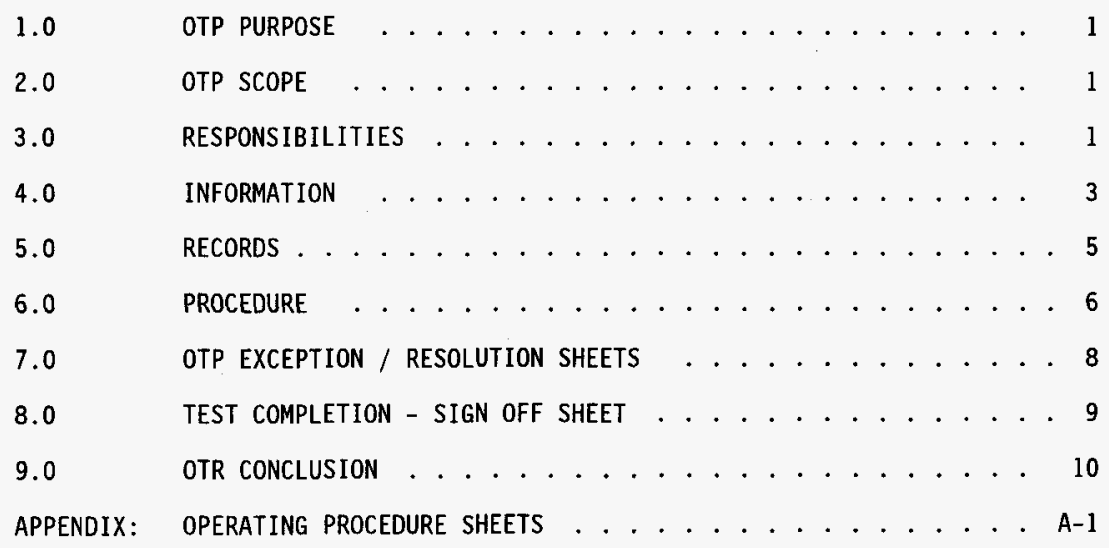

SUMMA is a Registered Trademark of Moletrics, Inc. 
WHC-SD-WM-OTR-196, REV 0

\subsection{PURPOSE}

The purpose of this Operability Test Procedure is to provide instructions for field testing of the In Situ Vapor Sampling System (ISVS), al so known as the Type 4 Vapor Sampling System. The procedure follows "Operability Test Procedures and Reports", contained in WHC-CM-6-1, standard Engineering Practices, EP 4.2 "Testing Requirements" Rev 5, Change 1.

\subsection{SCOPE}

Operability testing of the ISVS will verify that functional and operational requirements have been met. The test will show by demonstration that the ISVS is fully operational to perform the task of obtaining quality vapor samples from Hanford waste tanks. The test will be performed during a sample event in which ISVS and VSS will be operated concurrently on the same tank. This OTP and the side by side comparison are important parts of ISVS validation.

Concurrently, a special study will be conducted by PNL on the ISVS vapor sample probe and its performance under various conditions. The Operability Test Report (OTR) to be generated after testing will summarize the results of the operability test as well as the special study and the side by side sampling. The OTR will be the vehicle for acceptance of the ISVS in terms of field operability and a formal designation of its validation for technical adequacy.

\subsection{RESPONSIBILITIES}

Safety, Quality Assurance (QA), Characterization Project Operations (CPO), and Characterization Field Engineering (CFE) shall approve this procedure prior to release. Responsibilities are identified as follows:

Test Director $=$ D Dofors

Responsible for the overall performance of the OTP. Exercises stop work authority for unsafe activities or activities not conforming to this OTP. Directs the conduct and sequence of testing activities. Directs actions to be taken to prevent injury to employees or damage to equipment. Maintains cognizance of and documents test exceptions with concurrence of CFE Cognizant Engineer and the resolution of same. Concurs with all changes and with the acceptability and reliability of the equipment by signing the OTR. 
WHC-SD-WM-OTR-196, REV 0

CFE Cognizant Engineer (COG) $=E A N I L S E N \rightarrow D D W A N N E R$

Appoints Test Director. Controls the sequence in which the OTP is conducted through the Test Director with concurrence of the PIC. Provides technical expertise and advice to both the PIC and Test

Director as required. Maintains configuration control during testing. Approves any changes to the OTP. Responsible for obtaining additional support from engineering. Acts as the single point of contact for all engineering matters. Concurs with exceptions to testing on "OTP Exception List". Prepares and releases the OTR at conciusion of operability testing. Concurs with the acceptability and reliability by signing the OTR. A11 COG duties may be performed by COG's designee.

CPO Management - WJ KeNwE DY

Reviews and approves test procedure. Ensures effective safety meeting is held prior to test start. Monitors testing to extent approval may be given for satisfactory equipment operability and reliability.

CPO Person-In-Charge (PIC) = STEVE CARTER

Responsible for the assignment of personnel and directing all operations of the side by side sampling event and the OTP for the ISVS. Controls access to the test area in order to maintain a safe environment. Approves changes to the OTP in terms of operational steps or equipment configuration when requested by the Test Director. Conducts a pre-job safety meeting at the start of each shift during the performance of the OTP. Briefs the personnel on testing to be performed that day and associated hazards.

Quality Engineering = RON ARNDT (FIECD) AC TUSLL (EVALUKTERESURS)

Reviews and approves test procedure to assure compliance with applicable regulations. Concurs with exceptions and their resolutions jointly with Test Director and COG. QE (or designee) will witness and/or review performance of this procedure at their discretion.

Safety = JA HARVEY

Reviews and approves test procedure to assure compliance with applicable regulations. Concurs with exceptions and their resolutions jointly with Test Director and COG. Safety (or designee) will witness and/or review performance of this procedure at their discretion. 
WHC-SD-WM-OTR-196, REV 0

\subsection{INFORMATION}

\subsection{SYSTEM DESCRIPTION}

The system under test is the In Situ Vapor Sampling System. The system consists of a bundle of selected sorbent tubes to be lowered into the headspace of the chosen tank, a sample head assembly which protects the sorbent tubes, a pump and a flow measurement system. The pump used can be either the ISVS cart or the VSS: either is capable of drawing tank gases (essentially air with traces of other chemicals) through the HEPA filter, the sorbent trains, and the tubing bundle and measuring the volume of gas drawn. This test will be conducted using the ISVS cart, as the VSS will be involved in the Type 3 sampling event to be performed concurrentiy.

\subsection{TEST EQUIPMENT}

The equipment and materials listed below are necessary to perform this acceptance test:

- The VSS will be on the chosen tank, performing a normal Type 3 sampling event.

- A multiport adapter will be installed on the riser used for the Type 3 sampling. Type 4 sampling is to be performed through the other port on the same riser.

- For this test, the ISVS cart will be used to perform the Type 4 sampling.

- The work package(s) for the Type 3 and Type 4 sampling will specify a list of materials required. This OTP requires no special additional equipment. 
WHC-SD-WM-0TR-196, REV 0

\subsection{TEST GUIDANCE}

Discrepancies, deviations, or irregularities involving the test procedure and equipment performance are to be noted on the "OTP Exception / Resolution Data Sheet". These exceptions shall be jointly resolved between the Test Director, COG, and any assigned witnesses. All resolutions to the exceptions must be agreed upon by the responsible personne1, documented on the exception list, and initialed.

No testing shall be done which involves faulty equipment, as determined by the Test Director. However, at the discretion of the CFE Cognizant Engineer and with approval of the CPO PIC, tests may proceed on equipment which is not affected by fautty equipment.

If, due to circumstances, modifications of the test procedure are warranted, written changes may be made with the concurrence of the Test Director, COG, and any assigned witnesses. Amendments shall be per instructions in WHC-CM-6-1, Standard Engineering Practices, EP-4.2, "Testing Requirements" Rev 5, Change 1.

\subsection{REFERENCES}

WHC-CM-6-1 REV 5 Change 1, Standard Engineering Practices, EP-4.2

WHC-IP-1026 REV 1, Operability Test Procedures and Reports, Appendix L

WHC-SD-TD-ATP-132 REV 1, In Situ Vapor Sampling System Acceptance Test Procedure

H-2-825313 Vapor Sampling Cart Assembly

H-2-825314 Vapor Sampling Cart Electrical Installation

H-2-825301 In Situ Sample Head Assembly and Details

\subsection{SAFETY ISSUES}

Personal protective equipment and all other safety issues are covered in the work package(s) for Type 3 and Type 4 sampling. Any special safety issues related to the test (possible use of a tracer gas, or special sample handling for contaminated samples, etc) will be evaluated in the approval of the Sampling and Analysis Plan or other document which provides the details of the analytical plan.

\subsection{RADLATION ND CONTANIMATION CONTROL}

The RWP for routine vapor sampling activities applies for this test. 


\subsection{QUALITY ENGINEERING}

Quality Engineering shall approve this Operability Test Procedure prior to its release. A Quality representative shall witness and/or review test performance at their discretion.

\subsection{ACCEPTANCE CRITERIA}

The acceptance criteria for this OTP are the operability and predicted reliability of the equipment. Operability shall be determined on a simple "pass-fail" basis: each step shall be evaluated by the Test Director and COG to verify that the equipment is acceptable for continued use. Future reliability of the equipment is not determined quantitatively, but is accepted based on the judgment of the Test Director, COG, and CPO Manager, or their delegates. The judgment of acceptable overall reliability of the system shall be documented by the signatures on the Test Completion Sign-0ff Sheet.

\subsection{RECORDS}

The CFE Cognizant Engineer shall prepare and release an Operability Test Report at the conclusion of OTP testing as described in section 2. 


\subsection{PROCEDURE}

This procedure will be used to perform the operational testing of the ISVS system. As each step is performed initials shall be logged onto the procedure in the blank spaces as indicated. Those initialing here shall also sign the Test Completion - Signoff Sheet.

Step 1: Notify all witnesses immediately prior to commencing the test.

A Safety representative has been identified and will witness test or chooses not to.

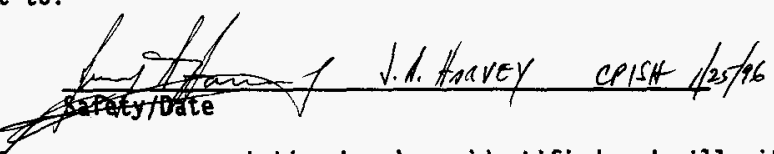

A Quality Assurance representative has been identified and will witness test or chooses not to.

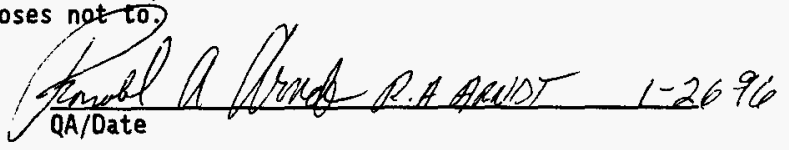

$O P / C E D P$ Step 2: The following conditions shall be met prior to conduct of this OTP:

VSS is prepared to perform a Type 3 sample event on the chosen tank.

ISVS cart is prepared to perform a Type 4 sample event on the same tank. 
oP/CE 99 SEL Step 3: The ISVS cart operating procedure does not normally require step-by-step signoffs. However, as this OTP is intended to verify the adequacy of the equipment and the procedure, a more rigorous examination of the procedure under field conditions is required. The ISVS cart operating procedure is written in a general manner, to allow for flexibility in sampling. Each section of the procedure is written to stand alone if necessary, and therefore each page will be performed repeatedly if several samples of the same type are taken. An OPERATIONAL COPY of the procedure shall be prepared before the sample job with sufficient copies of each page to allow the sample job to be completed without having to perform multiple checkoffs on each sheet.

Proceed with the Type 4 sample event, using the OPERATIONAL COPY, marking off the steps as they are accomplished. A' check mark beside each step shall be considered adequate documentation of step completion: the person making the check marks shall initial each page as it is completed. Due to the nature of the OPERATIONAL COPY, there will be steps on some pages that do not apply. These shall be lined out. Any SIGNIFICANT difficulty encountered in performing the procedure shall be resolved, then recorded as an exception with its resolution, and sampling shall continue.

OP/CEDI YRP Step 4: VERIFY that all steps in the OPERATIONAL COPY of the procedure have been completed. This completes the Operational Test Procedure. 
WHC-SD-WM-OTR-196, REV O

OTP EXCEPTION / RESOLUTION DATA SHEET

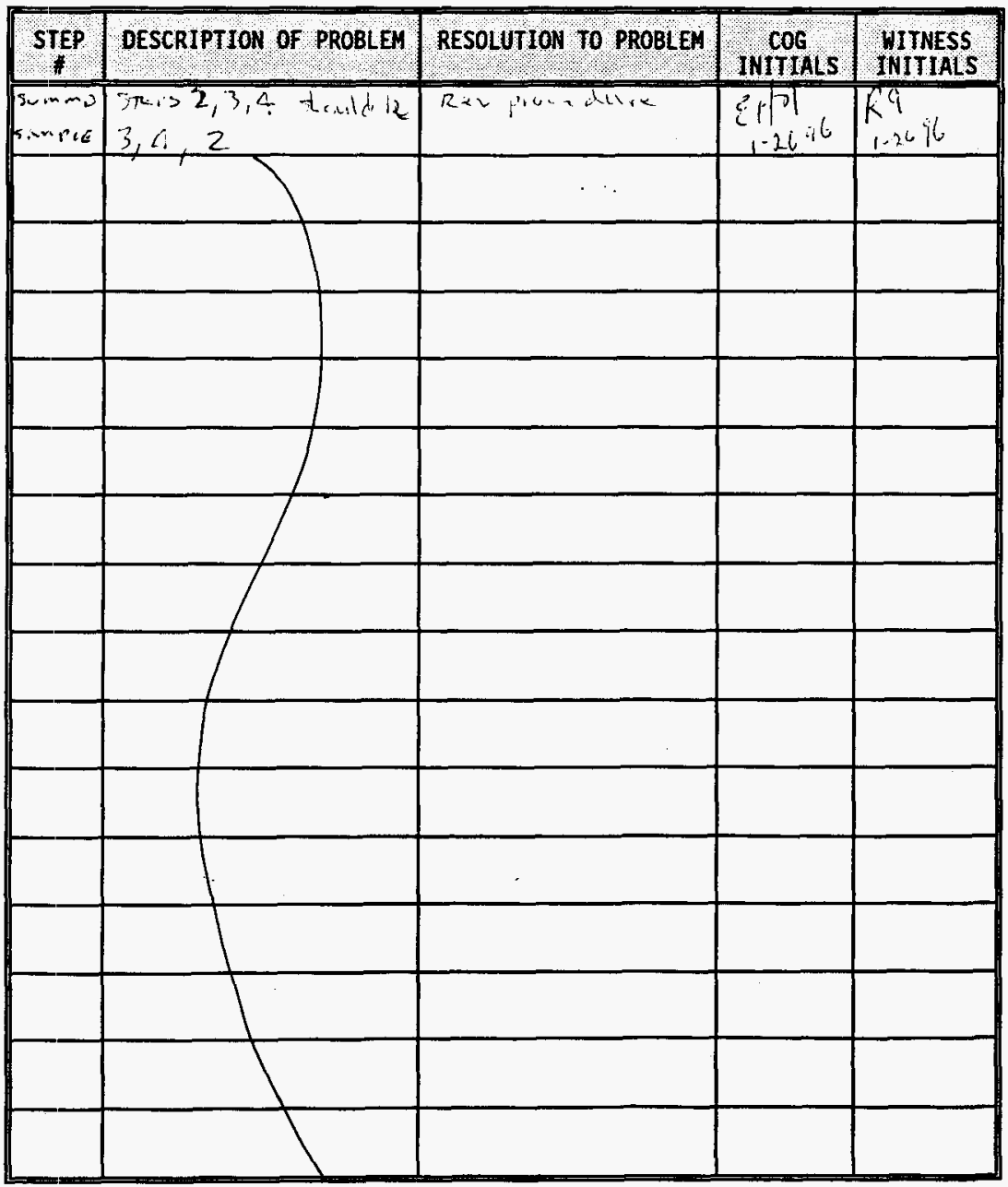




\section{TEST COMPLETION - SIGN OFF SHEET}

All tests have been completed as described in this OTP. All exceptions have been documented and resolved as indicated on the "OTP Exception / Resolution Sheet". The ISVS can be operated in a safe manner and pose no unacceptable hazards to the operator. System reliability is predicted to be acceptable.

\begin{tabular}{|c|c|c|c|}
\hline . NAME & ORGANIZATIOH & SIGNATURE & DAIE \\
\hline DK DEFORD & $\begin{array}{l}\text { Characterization Equipment Development } \\
\text { (PROJECT ENGINEER) }\end{array}$ & & $1 / 26 / 96$ \\
\hline WJ KENNEDY & Characterization Project Operations (MGR) & & $2 / 12 / 96$ \\
\hline SB CARTER & Characterization Project Operations (PIC) & & $2 / 12 / 96$ \\
\hline AC TUELL & Quality Assurance & & $2 / 20 / 90$ \\
\hline JA HARVEY & Safety & & $2 / 12 / 96$ \\
\hline JS SCHOFIELD & Characterization Field Engineering (MGR) & & $2 / 22 / 96$ \\
\hline EH HEIfSEN & Characterization Field Engineering (COG) & & \\
\hline
\end{tabular}




\subsection{OTR CONCLUSION}

The OTP was successfully completed on January 26, 1996. The ISVS operability test was performed in parallel with an operational VSS sampling event, as described in section 2.0. Vapor samples were collected from.Tank C-107 on January 17, 1996; from Tank BY-108 on January 23, 1996; and from Tank S-102 on January 26, 1996. The three tanks were sampled by both the VSS and ISVS methods from the same access risers within the same eight-hour period. These Tanks were selected because their headspace compositions are diverse, and they represent the highest known levels of several key vapor analytes. Because samples were collected when ambient temperatures were at or below freezing, this test demonstrated the operability of the ISVS method during one of the most adverse field conditions.

The acceptance criteria for the ISVS operability test was met during each sampling event, and is documented per the requirements described in section 4.7. The only exception/resolution noted in section 7.0 was due to an error in the operating procedure. This problem was resolved by an ICA (instruction change authorization) to the operating procedure. Final acceptance of test completion and overall reliability of the system was completed February 22 , 1996, per section 8.0.

The OPERATIONAL COPY of the operating procedure, used for step-by-step completion of the sampling event, is provided as the appendix to this report. This procedure was followed and marked according to the instructions given in step 3 of the OTP. The procedure pages in the appendix are in the order that they were assembled for the sampling events. Because samples were collected by the sampling crew using the revised operating procedure, this test demonstrated personnel and procedure readiness.

In addition to the operability testing described above, ISVS testing was performed by PNNL. The special study referred to in section 2.0 and the bench testing referred to in WHC-SD-WM-ETP-193 was performed by PNNL after ATP and prior to OTP. This informal testing resulted in the conclusion that the equipment was ready to support the OTP and that all test information required to support the operational deployment of the system would be obtained in the OTP and by a side by side sampling comparison. This comparison test (referred to as the field cart test in WHC-SD-WM-ETP-193) was analyzed by. PNNL. The two sampling methods compared in this test are the truck-mounted vapor sampling system and the cart mounted ISVS. The results of this test are documented in the report "Comparison of Vapor Sampling System (VSS) and In Situ Vapor Sampling (ISVS) Methods on Tanks C-107, BY-108, and S-102 (PNNL-11186) by J. L. Huckaby, et al. This conclusion of this report is summarized in the following two paragraphs.

Results from the two comparison criteria used to evaluate the comparability of the VSS and the ISVS methods indicate that the ISVS method is essentially equivalent to the VSS method. Of 65 comparisons, 56 ( 86 percent) passed the acceptance criteria. The three dominant vapor space waste constituents (i.e., ammonia, hydrogen, and nitrous oxide) are among those passing the acceptance criteria with sample results very close to the VSS method. Gases and vapors that met the acceptance criteria in all tanks include ammonia, water vapor, 
and the permanent gases. Relative percent differences between the sample method means ranged for ammonia and water vapor between three and eight percent, and for the permanent gases from 0.3 to two percent. Total nonmethane hydrocarbon results also met the criteria, except samples from Tank C-107 where contamination from adhesive tape used to seal the sample tube bund le caused results outside the acceptance criteria. An alternate sealing method has since been developed. Most of the organic vapors collected by SUMMA ${ }^{T M}$ canister also met the comparison criteria. of those organic vapors outside the acceptance criteria (five of 29 ), two semivolatile organic vapors experienced low transfer to the sample canister through unheated tubing on a very cold day and three demonstrated no trend toward lower or higher concentrations than the VSS sample method (i.e., no consistent bias). Most organic vapors collected by triple sorbent traps (TSTs) also met the acceptance criteria. Seven of 20 results exceeded the acceptance criteria, but also demonstrate no trend toward lower or higher concentrations than the VSS method (i.e., no consistent bias). Those organic vapor results outside the acceptance criteria collected by either ISVS TSTS or ISVS SUMMA ${ }^{\text {TM }}$ canisters were considered acceptable, since the difference between VSS TST and VSS SUMMA ${ }^{T M}$ canister sample results were generally greater than the differences between the VSS and ISVS methods.

As was anticipated, certain semivolatile organic vapors in Tank BY-108 were not quantitatively transferred through the ISVS transfer tubing to SUMMA ${ }^{\text {TM }}$ canister samples. Future analyses of semivolatile organic vapors in SUMMA ${ }^{\text {TM }}$ canisters collected by the ISVS method should thus be considered suspect if their concentrations are very high, as was the case in Tank BY-108. In such situations either the semivolatiles should be measured using the TST samples, or the VSS should be used to collect SUMMA ${ }^{\mathrm{TM}}$ canister samples. Tests of the ISVS system with and without a particulate filter were conducted to assess the removal of tributyl phosphate and other semivolatile organic vapors by the filters. The filters are necessary in the VSS method to prevent contamination of the sampling system, but can be eliminated in the ISVS method because of the ease of system decontamination. Results indicated that the filters did adversely affect the collection of low volatility organic vapors, however, because tributyl phosphate was not detected in any of the samples (filtered or unfiltered), the effect of the filters on tributyl phosphate could not be determined. Because of the effect on low volatility organic vapors, the ISVS samples without the particulate filter are used in the comparison study. Future production sampling should be conducted without the filters.

The above PNNL report briefly mentions two problems associated with the initial use of the ISVS method (adhesive tape off-gassing and imperfect SUMMA ${ }^{T M}$ transfer line connections). These problems were not considered a significant difficulty during operability testing and require no further resolution. The ISVS sampling is further discussed in the following three reports: WHC-SD-WM-RPT-216, -217 , and -218 . Based on a 11 ISVS testing to date, the conclusion of this report is that the ISVS system, including the associated support personnel and work procedures, is ready for operational deployment as described in WHC-SD-WM-ETP-193. 
WHC-SD-WM-OTR-196 REV. 0

APPENDIX A

\section{OPERATING PROCEDURE SHEETS}

OPERATIONAL COPY

$A-i$ 


\section{INSTRUCTION CHANGE AUTHORIZATION (ICA)}

\section{CA No. \\ $1 P-6$}

Instruction No.

WHC-IP-1127, 4.8, "Vapor Sampling of Waste Tanks Using In Situ Sampling System (ISVS)"

Description of Change

Rev. No.

Page 1 of 2

Approval Designator

$S / Q$

The term "HEPA" was incorrectly used in this procedure and should be deleted from this procedure. Delete all occurrences of "HEPA" in the procedure.

Page 4, Section 7.0 EQUIPMENT, add the following:

filter - glass fiber filters, Type $A / E$, Nominal Rating (1iquids) $=1$ micro meter

filter - PTFE membrane, 2 micro meter, Typical Aerosol Retention of $99.99 \%$ for 0.3 micro meter (DOP) at $32 \mathrm{Lpm} / 100$ square $\mathrm{cm}$.

Page 9, FOR SUMMA SAMPLING, Step 3b. Change "150" to " 45 ".

Page 9, FOR SORBENT SAMPLING, Step 3c. Delete this step.

Page 10, Step 5. Change "150" to " $45 "$.

Page 11, Add Step 21a. "Wait 5 minutes before closing c-flex clamps and removing sample line (step 24)."

Page 12, Step 5. Change "150" to " 45 ".
[] One Time
[X] Permanent

Justification

The filters being used in the procedure are not HEPA filters. The term was used incorrectly in this procedure and must be deleted from this procedure.

The flow changes will allow the procedure to follow the direction of the TSAP for C107 , BY-108 and S-102. The flow changes will al so improve operational efficiency. Adding step 21 a will allow the tube bundle tubing to come back up to tank pressure, correcting for any evacuated pressure in the tubing due to a tightiy packed TST. The data sheet was added because there was no place to record data on the original

procedure.

Approvals: (Print/Sign Name and Date)

RD Mahon

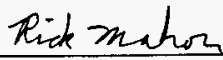
ICA Author

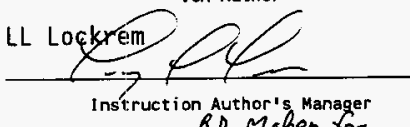

DL Edwards In OL EdwardS Ren telecon 11:50 Am

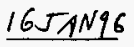

Date
LL Loekrem

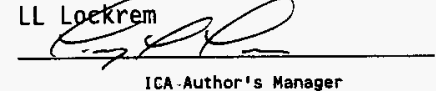

ICA-Author's Manager

CJ Stephan

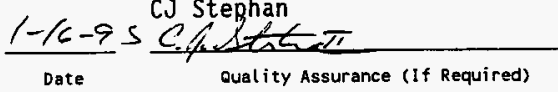

$\frac{165 A N 96}{\text { Date }} \frac{\text { PA-Hoomaten }}{\text { Safety (If Required) }}$

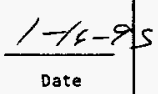

$1-16-74$

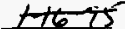

Date

$1-16-96$

Date 
WHC-SD-WM-OTR-196, REV. O

\section{INSTRUCTION CHANGE AUTHORIZATION (ICA)}

Instruction No.

WHC-IP-11.27, 4.8, "Vapor Sampling of Waste Tanks Using In Situ Sampling System (ISVS)"

Description of Change (eontinued)

Add a data sheet to the procedure (Attached to ICA) for use with Appendix III, Sorbent Tube Sampiling. 
WHC-SD-WM-OTE-196, REV.O

TANK

DATE

TIME

\begin{tabular}{|c|c|c|c|c|}
\hline Sarnple \# & Port \# & $\begin{array}{c}\text { Start } \\
\text { Time }\end{array}$ & $\begin{array}{c}\text { Stop } \\
\text { Time }\end{array}$ & $\begin{array}{l}\text { Totalizer } \\
\text { Volume }\end{array}$ \\
\hline & 1 & & & \\
\hline & 2 & & & \\
\hline & 3 & & & \\
\hline & 4 & & & \\
\hline
\end{tabular}

\begin{tabular}{|c|c|c|c|c|c|c|c|c|c|}
\hline TIME & FM-1 & FM-2 & FM-3 & FM-4 & $\overline{T-1}$ & T-2 & $T-3$ & $T-4$ & $\mathrm{PI}-1$ \\
\hline & & & & & & & & & \\
\hline & & & & & & & & & \\
\hline & & & & & & & & & \\
\hline & & & & & & & & & \\
\hline & & & & & & & & & \\
\hline & & & & & & & & & \\
\hline & & & & & & & & & \\
\hline & & & & & & & & & \\
\hline & & & & & & & & & \\
\hline & & & & & & & & & \\
\hline & & & & & & & & & \\
\hline & & & & & & & & & \\
\hline & & & & & & & & & \\
\hline & & & & & & & & & \\
\hline & & & & & & & & & \\
\hline
\end{tabular}




\subsection{SUMMARY}

The following sampling procedure is used to collect samples of vapors in the underground waste storage tanks at Hanford. Sampling will be directed by a Tank Characterization Plan (TCP). The TCP is provided by the organizations requesting the tank vapor characterization. Samples can be collected by sorbent tubes, SUMMA" canisters, or flow-through cylinders under this procedure.

\subsection{APPLICATIONS}

This procedure provides direction only to Sampling and Mobile Laboratories (S\&ML) and Special Analytical Studies (SAS) personnel who have been trained in the operation of the In Situ Vapor Sampling System (ISVS).

\subsection{LIMITATIONS}

This procedure is limited to waste tank vapor characterization efforts supported by protocol sampling. A TCP provided by Characterization Management shall be written for each sampling effort that specifies the operational ISVS parameters.

\subsection{QUALITY CONTROL PROTOCOL}

All sampling activities shall be performed in accordance with the requirements established in the project specific Quality Assurance Project Plan (QAPjP) and TCP.

Collected samples shall be labeled, evidence-taped, and maintained under chain-ot-custody (COC) by S\&ML personnel from the time of collection. COC shall be initiated and maintained in accordance with Section 1.3, "Chain of Custody for RCRA/CERCLA Protocol Samples," of this manual.

Quality control samples shall be collected as specitied in the project specific QAPjP.

\subsection{SAFETY}

All vapor sampling activities shall he performed in accordance with site-specitic health and safety and radiological work permit (RWP) requirements. As applicable, these documents will include WHC procedures and U.S. Department of Energy safety requirements for access control, radioactive and hazardous waste monitoring, personal protective equipment (PPE), operations, containment, and decontamination.

\subsection{RESPONSIBILITIES AND INTERFACES}

\subsection{Health Physics Technicians (HPTs)}

- Supply appropriate RWP to conduct sampling, as appropriate.

SUMMA is a trademark of Molestrics, Inc.. Cleveland, $\mathrm{OH}$. 
WHC-SD-WM.OTR-196, REV.

WHC-IP-1127, Sampling and Mobile Laboratories Procedures

Monitor sampling activities to ensure the radiological health and safety of the sampling team.

Assess dose rates of sample containers and transport vessel to ensure compliance with regulations.

- Sign the Onsite Routine Radioactive Shipment Record and Request for Special Analysis form (it applicable).

- Survey samples, sampling equipment, and sampling personnel out of radiation zones, in a timely and etticient manner.

- Provide the appropriate release stickers tor samples and used equipment.

- Sign Otf-Site Property Control fiorm, if applicable.

\subsection{Tank Farms Operations}

- Provide a qualified persun-in-charge (PIC) to oversee field activities.

- Coordinate with HPTs and Industrial Hygiene to ensure appropriate support is made available.

- Provide PPE as required by the applicable RWP.

- Provide electrician support for honding and grounding ISVS if required.

- Conduct a pre-job safety meeting.

\subsection{Field Scientist}

- Conduct overview of the TCP.

- Direct sampling event(s).

- Document and communicate to coynizant management, any anomalies or situations that may compromise the integrity of the samples.

- Review all documents hefure release from the originating organization.

- Document all pre-job, joh specific, and post-job activities associated with the sampling event(s).

- Ensure samples and sampling equipment are transported to and from the sample site.

- Ensure a copy of the TCP is available fior reference during sampling. 
WHC-SD-WM-OTR-196, REV. O

WHIC-IP-1127, Sampling and Mobile Laboratories Procedures

- Ensure logbook is maintained.

- Perform overall operation of ISVS.

- Coordinate analysis of high efficiency particulate air (HEPA) filters through the 222-S Laboratory.

- Provide the deliverables to the Manager of S\&ML.

\subsection{Sample Technician(s)}

- Assist the field scientist in gathering necessary supplies and equipment to complete the sampling event.

- Assist in the operation of the ISVS.

- Photograph the sampling point. Lahel the photograph(s) with the date, location, and time. Sign and date the photograph(s).

- Review, date, and initial all documentation.

- Label and package samples.

\subsection{Laboratories}

\subsubsection{Off-Site Laboratories}

- Provide all sample media that has heen cleaned or prepared in accordance with QAPJP requirements.

- Maintain certificate of cleanliness of the sample collection media.

- Initiate COC for sample media.

- Analyze samples, preparte and submit analytical results.

\subsubsection{On-Site Lahoratories}

- Initiate identifiers-for radiation screening samples.

- Analyze samples for radiological activity and provide results for release and shipping criteria. 
WHC-SD-WM-OTR-A6, REV. O

WHC-IP-1127, Sampling and Mohile Laboratories Procedures

Rev. 0

Vapor Sampling of Waste Tanks Lsing

May 5, 1995

In Situ Vapor Sampling System (ISVS)

\subsection{EQUIPMENT}

$$
\text { Tank S-COA }
$$

The following is a typical list of equipment that may be used in the collection of samples.

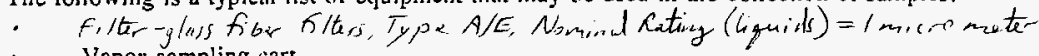

- Vapor sampling cart

- Tube bundle (length specified in the work package)

- Sample collection media

- Field data forms

- Copy of sampling procedure

- Hand tools PTFE mambrane 2 micromater Typical Aerosol Retention of $9799 \%$

\subsection{PROCEDURE STEPS}

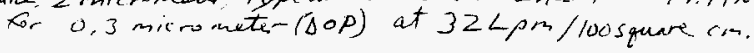

\subsection{Setup}

$f^{n} v_{1}$. Check sample cart insmumentation for current calibration.

qu V/. Clamp otit all sample lines at the sample cart end.

D- $\sqrt{3}$. EnsurefHEPh tilters are in HEPA filter boydies F-1 through F-5.

$\hat{f}^{-} \sqrt{4}$. Ensure HEPA-filters are positioned in Sample Head.

$f-\sqrt{5}$. Take the equipment into the farm and position it for sampling.

f. V6. Vapur sampling cart must be positioned level outside of the containment structure.

iv $\checkmark 7$. Ensure Electricians have honded and grounded the ISVS if required.

f. $\sqrt{ } / 8$. Suply electricity to sample cart.

$\because \sqrt{9}$. Pertirm leak test (see Appendix 1).

i. $V_{10}$. Ensure valve V-8 remins closed for all procedures. This valve is to be used as an auxiliary vacuum port only and may effect sampling if left open.

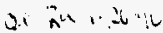

\section{S.1.1 Tulse Bundle Plicement}

NOTE: The tuhe hundle is still under "COC and the responsihility of the sampling team. It is essential that it he visually monilored throughout the insertion into the lank and during removal.

1. If simpling from ventilation dut with a pitot tuhe, see Appendix VI. If not, proceed to siep 2.

2. Supply the tuhe hundle to the Operations PIC. 
WHC-5D-WM-OTR-196, REV.O

WHC-IP-1127, Sampling and Mobile Laboratories Procedures

Vapor Sampling of Waste Tanks Using

In Situ Vapor Sampling System (ISVS)

Rev. 0

May 5, 1995

Page 8 of 16

APPENDIX 1

LEAK TEST

Tank $\overline{2}-102$

Date $\leq 6$ in:

Time $0 ? 12$

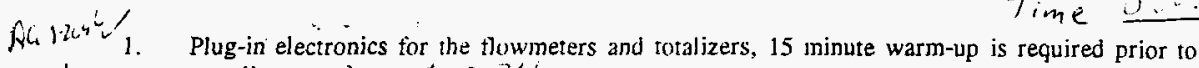
sampling. $n^{t} \div ? / 0$

$\hat{\imath}^{-} \cdot / 2$

Ensure cart is not connected to the tube bundle, then place a short section of C-tlex with a closed clamp on sample ports 1 thru 5 .

$i^{4} \quad V_{3}$. Ensure SUMMA" Sampling Station is securely capped.

A. 4. Open valves V-1, V-2, v-3, V-4, V-5, v-6 and V-7.

$1 c$ is. Close rotameter needle valves FG-1, FG-2. FG-3, FG-4, and FG-5.

K 6. Turn ON the sample pump.

I4 Vh. Slowly open rotameter needle valves FG-1. FG-2. FG-3, FG-4 and FG-5 to full on-position.

$j^{2}$ - 8. Let pump run for two minutes.

kit 19 . Close valve V-7.

i. To. Turn OFF vacuum pump.

1iv

11

Record vacuum pressure from PI-1 in tield notes (approx. 23.5 in. $\mathrm{Hg}$ ).

PI- 1 start $24.5 i$

i. Wait tive minutes.

is 13. Record tinal vacuum preskure from $\mathrm{Pl}-1$.

i) 14 . If the pressure gain is greater than $\mathrm{l}$ inch $\mathrm{Hg}$ in 5 minutes, troubleshoot and repeat test.

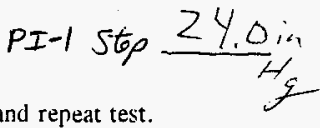

15. Remove jumpers and close valves $V-1, V-2, V-3, V-4, V-5, V-6$ and $V-7$. The system is now $1.26-96$ in stand-by mode. 
WHC-SD-WM-OTR-196, REV. $O$

WHC-IP-1127, Sampling and Mobile Laboratories Procedures

4.8

Vapor Sampling of Waste Tanks Using

Rev. 0

In Situ Vapor Sampling System (ISVS)

May 5, 1995

Page 9 of 16

\section{APPENDIX II \\ SETTING SYSTEM FLOW RATES}

$i_{1} \quad i-2 \cdot i t$

FOR SUMMA“ SAMPLING

Bundle A Ambient

1. From Stand-hy Mode, open valve V-5, V-6.

$i^{h} \quad-2$ Ensure valves V-1, V-2, V-3 and V-4 are closed.

$F^{\cdots} \quad / 3$. Without SUMMA line connected to sample port 5 :

a. Turn on sample pump and open valve V-7. 45 ( $1 \mathrm{~L}$ F/ow Rate)

b. Adjust rotameter FG-5 to the desired tlow range (usually the 150 mark).

c. Allow system to purge for the desired time.

Close valve V-7, V-5 and V-6.

.e. Turn OFF the sample pump.

$y$ - 4 . Connect wire re-enforced teflon line in tube bundle to SUMMA" sample port.

fif ${ }^{5}$. System is operational for SUMMA* sampling.

\section{FQR SORBENT SAMPLING}

1. From Stand-by Mode, open valves V-1, V-2, V-3, and V-4

2. Ensure valve $\mathrm{k} Q$ is closed.

3. With no sample lines comected to the sample ports:

a. Turn ON the sample pump.

b. Open valve V-7

c. Open rotameters FG-1, FG-2, FG-3, and FG-4 to tull on position.

(1. With the rotameter needle valves (FG-1 threugh FG-4), adjust the flow rate, indicated by the Flowmeter, to the desired thow range.

e. Ensure the totalizers are counting flow volume.

f. Cluse valve V-1, V-2, V-3, V-4 and V-7.

g. Turn OFF the sample pump.

4. System is uperational for sorbent sampling. 
WHC-SD-WM-OTR-196, REV. O

WHC-IP-1127, Sampling and Mobile Laboratories Procedures

Vapor Sampling of Waste Tanks Using

Rev. 0

In Situ Vapor Sampling System (ISVS)

May 5, 1995

Page 12 of 16

Cnnister *123: SUMMA" APPENDIX IV

1. From Stand-by Mode, remove cap from the SUMMA- Sampling Station and connect the SUMMA" canister.

2. Open valve $\mathrm{V}-5$ and $\mathrm{V}-6$.

$T 1=-1.22^{\circ} \mathrm{c}$

3. Start sample pump.

4. Open valve V-7

5. Slowly increase FG-5 to unit mark +50

6. Let purge for $\$$ minutes.

Bundle A Ambient
Tank $:-i \geq$
Date $\frac{2511096}{0 \$ 5}$

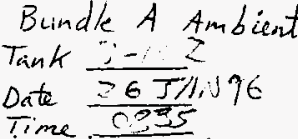

*Periodically check carbonidryrite cylinder for gross liquid contamination during tank gas purge.

Shut down system should this occur.

7. Close valves $V-6$ and $V-7$.

8. Turn off sample pump.

L. Reser Stopwatch

10. Simultaneously: Open SUMMA canister valve Start Time $=0.841$ Start Stopwatch

T1. Allow 60 seconds for canister to fill.

42. Close the SUMMA" canister valve.

$$
\text { Stop Time }=\frac{0342}{\operatorname{cji} 2} \begin{aligned}
\text { Hapor } & =4,6 \\
\text { Hiad } & =30.3
\end{aligned}
$$

13. Close valve $V-5$.

14. Remove the exposed SUMMA" canister and replace SUMMA" station cap or install next SUMMA" sample and repeat procedure at step 2.

15. Record any anomalies in tield notes.

16. Return to standhy inode (Section 8.2). 
WHC-SD-WM-OTR-196, REV. O

WHC-IP-1127, Sampling and Mobile Laboratories Procedures

4.8

Vapor Sampling of Waste Tanks Using

Rev. 0

In Situ Vapor Sampling System (ISVS)

May 5, 1995

Page 9 of 16

\section{APPENDIX II \\ $\because \because$ \\ SETTING SYSTEM FLOW RATES \\ Bundle B Ambient}

FOR SUMMA" SAMPLING

if twiwi. From Stand-by Mode, open value V-5, V-6.

$i$ : Ensure valves V-1, V-2, V-3 and V-4 are closed.

ic - Without SUMMA line connected to sample port 5:

La. Turn on sample pump and open valve V-7. 45

b. Adjust rotameter FG-5 to the desired thow range (usually the 150 mark).

c. Allow system to purge for the desired time.

d. Close valve V-7, V-5 and V-6.

ve. Turn OFF the sample pump.

in 4 . Connect wire re-enforced tetlon line in tube bundle to SUMMA" sample port.

in $f^{-16-5}$. System is operational for SUMMA* sampling.

FQR SORBENT SAMPLING

1. From Stand-hy Mode, open valves V-1, V-2, V-3, and V-4

2. Ensure valve $\times 6$ is closed.

3. With no sample lines conneted to the sample ports:

a. Turn ON the sample pump.

b. Open value $V-7$

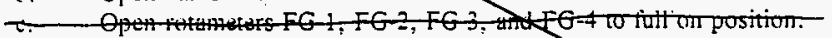

d. With the rotameter needle valves (FG-1 through FG-4), adjust the flow rate, indicated by the Fluwmeter, to the desired tlow range.

e. Ensure the totalizers are counting tlow volume.

f. Cluse valve $V-1, v-2, V-3, V-4$ and $V-7$.

I. Turn OFF the sample pump.

4. System is operational for sorbent sampling. 
WHC-SO-WM-OTR-196, REV. O

WHC-IP-1127, Sampling and Mobile Laboratories Procedures

Vapor Sampling of Waste Tanks Using

In Situ Vapor Sampling System (ISVS)
Rev. 0

May 5, 1995

Page 12 of 16

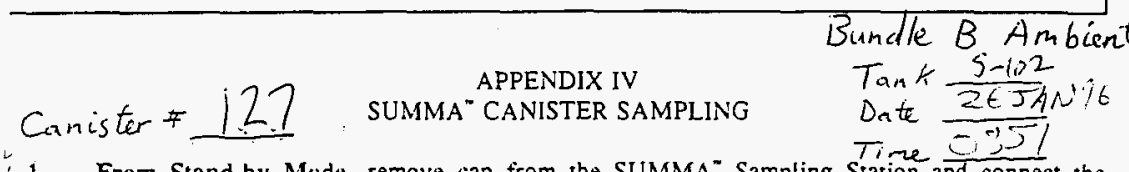

A.t. F 1 . From Stand-by Mode, remove cap from the SUMMA" Sampling Station and connect the SUMMA* canister.

ii $=/ 2$. Open valve $V-5$ and $V-6$.

1. 3. Start sample pump.

$i^{2}$. 24. Open valve V-7

ii $V$ Slowly increase FG.5 to unit mark 150

$f^{-} / 6$. Let purge for $5^{5}$ minutes.

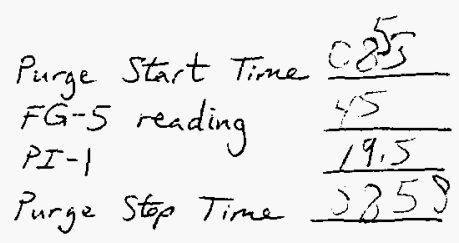

*Periodically check carbonldryrite cylinder for gross liquid contamination during tank gas purge.

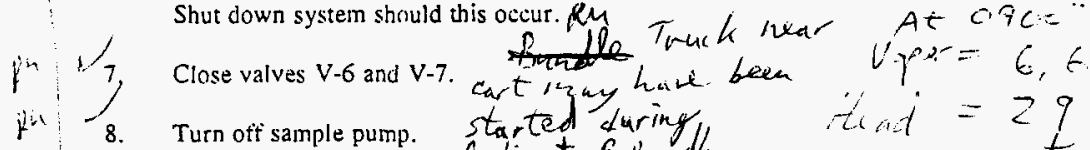

in 8. Turn off sample pump. started during in ai $=29$

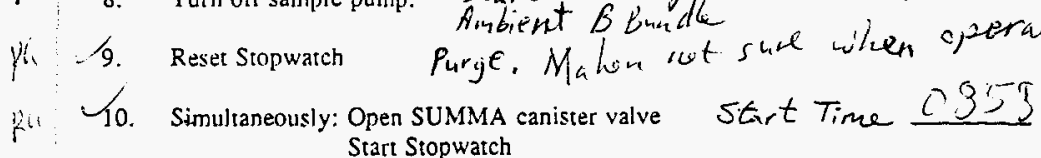

ji: 11. Allow 60 seconds for canister to till.

$k$. M2. Close the SUMMA canister valve. Stop Time a 39

$k_{2}$ : $\alpha_{13}$. Cluse valve $v-5$.

Fil ${ }_{14}$. Remove the exposed SUMMA" canister and replace SUMMA" station cap or install next SUMMA" sample and repeat procedure at step 2.

1.il 15 . Record any anomalies in tield notes.

16. Return to standhy mide (Section 8.2).

i $2 i$ 
WHC-SD-WM-OTR-196, REV. O

WHC-IP-1127, Sampling and Mobile Laborotories Procedures

4.8

Rev. 0

Vapor Sampling of Waste Tanks Using

May 5, 1995

In Situ Vapor Sampling System (ISVS)

Page 9 of 16

\section{APPENDIX II \\ SETTING SYSTEM FLOW RATES}

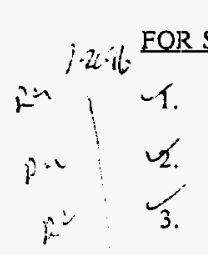

Bundle C Ambient

in $\quad \begin{aligned} & -1 . \\ & j \times\end{aligned}$

From Stand-by Mode, open valve V-5, V-6.

Ensure valves V-1, V-2, V-3 and V-t are closed.

Without SUMMA" line connected to sample port 5 :

3. Turn on sample pump and open valve $V-7$. 45

7. Adjust rotameter FG-5 to the desired tlow range (usually the 150 mark).

c. Allow system to purge for the desired time.

J. Close valve V-7, V-5 and V-6.

e. Turn OFF the sample pump.

Fi: L. Connect wire re-enforced teflon line in tube bundle to SUMMA" sample port.

itili 5 . System is operational for SUMMA* sampling.

\section{PQR SORBENT SAMPLING}

1. From Stand-loy Mnde, open valves V-1, V-2, V-3, and V-4

2. Ensure valve $\times-6$ is closed.

3. With no sample lines compected to the sample ports:

a. Turn ON the sample pump.

b. Open valve V-7

T. OP

d. With the rotameter needle valves (FG-1 through FG-4), adjust the flow rate, indicated by the Flowmeter, to the desired tlow range.

e. Ensure the totalizers are counting thow volume.

f. Cluse valve V-1, V-2, V-3, V-4 and V-7.

s. Turn OFF the sample pump.

4. System is uperational for sorbent sampling. 
WHC-SD-WM-OTR-196, REV. $O$

WHC-IP-1127, Sampling and Mobile Laboratories Procedures

4.8

Rev. 0

Vapor Sampling of Waste Tanks Using

May 5, 1995

In Situ Vapor Sampling System (ISVS)

Page 12 of 16

\footnotetext{
Bundle C Ambient

i.l Canister $\$ 165$. SUMMA* CANISTER SAMPLING

1.- 1 . From Stand-by Mode, remove cap from the SUMMA* Sampling Station and connect the SUMMA" canister.

in 2 . Open valve V-5 and V-6.

j: $v_{3}$ Start sample pump.

Riv 4 . Open valve v-7

ic $/ 5$. Slowly increase FG-5 to unit mark tio.

Let purge for $\not{Z}$ minutes.

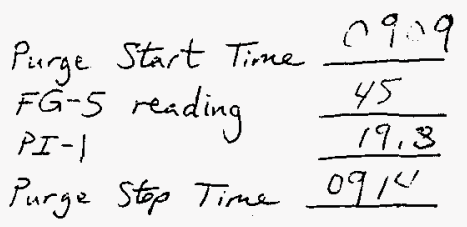

*Periodically check carbonldryrite cylinder for gross liquid contamination during tank gas purge. Shut down system should this occur.

$\checkmark$ Close valves $V-6$ and $V-7$

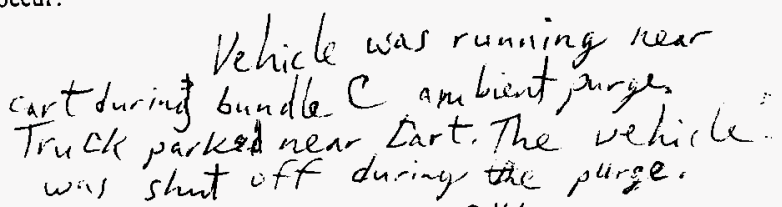

9. Reset Stopwatch way shot off during the plirge.

10. Simultaneously: Open SUMMA canister valve start Time $\mathrm{O} / 4$ Start Stopwatch

$1:$ Víl. Allow 60 seconds for canister to till.

ic $V_{12}$. Close the SUMMA" canister valve.

Stop Time 0915

473. Chose villue v-s.

$r$

12 UX4. Remove the exposed SUMMA* canister and replace SUMMA" station cap or install next SUMMA" sample and repeat procedure at step 2.

Fin 15. Record any anomalies in field notes.

1.2. Return to standihy mode (Section 8.2).
} 
WHC-SD-WM-OTR-196, REV. O

WHC-IP-1127, Sampling and Mobile Laboratories Procedures

Vapor Sampling of Waste Tanks Using

\section{ZO EQUIPMENT}

The following is a typical list of equipment that may be used in the collection of somples.

\subsection{PROCEDURE STEPS}

\subsection{Setup}

Vapor sampling cart

- Tube bundle (length specified in the work package)

- Sample collection media

- Field data forms

- Copy ot

- Hand tools

1. Check sample cart insrrumetration for cyrrent calibration.

2. Clamp otf all sample lines at the vinple cart end.

3. Ensure HEPA tilters are in HEPA tiliex hodies F-1 through $\dot{\mathrm{F}}-5$.

4. Ensure HEPA filters are fositioned in Sample Head.

5. Tike the equipment/nto the farm and position it fer sampling.

6. Vapor samplins cart must be positioned level outside ofithe containment structure.

7. Ensure Electricians have honded and grounded the ISVS if required.

8. Suppry electricity w simple cart.

9. Pertirm le:ik test (see Appendix I).

16. Ensure valve V-8 remains closed fur all procedures. This valve is to be ysed as an auxiliary vacuum port only and may effect sampling if left open.

\subsubsection{Tuhe Bundle Placement ${ }^{\text {Insert }}$ Bund/e $A$}

NOTE: The cuhe bundle is still under COC and the responsibility of the sumpling team. It is essemtial that it be visually monitored throughout the insertion into the tanki and during remuval.

$=A_{1}$

$\therefore \because \gamma_{2}$
If samplin! from ventilation duct with a pitot tube, see Appendix VI. If not, proceed on step 2.

Supply the whe hundle w the Operations PIC. 
A. L 2 . Monitor the placement of the tube bundle in the containment structure.

$1412 \therefore 4$. Monitor the tube bundle during insertion to ensure Operations placement at the correct depth/location, per TCP instructions.

5. In the field notes, record the;

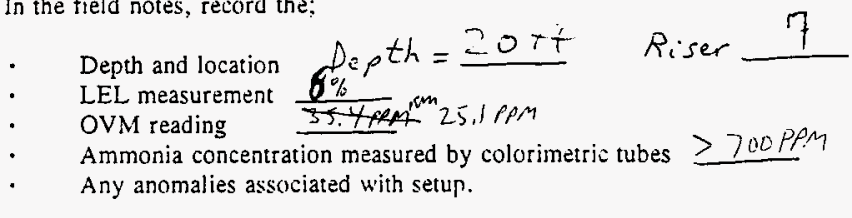

\section{-8.2 Standloy Minde}

During the standby mode the sample cart shall be ready for operation and in the following contiguration:

a. Tube bundle is in the sampling position/location in the tank but not connected to the cart,

b. Valves V-1, V-2, V-3, V-4, V-5, V-6 and V-7 are closed.

v. Sample pump is off.

- Power is on to the flowmeters and totallizers

$\because+2$. The standby mode serves as a reference point from which the following functions can be performed.

\begin{tabular}{|l|c|}
\hline \multicolumn{1}{|c|}{ Description } & Appendix \\
\hline Leak Test & I \\
\hline Setting System Flow Rates & II \\
\hline Sorbent Tube Sampling & III \\
\hline SUMMA" Canister Sampling & IV \\
\hline Flow-Through Cylinder Sampling & V \\
\hline
\end{tabular}

\subsection{Shutdown}

1. Request HPT coverage during stens 2 through 6.

2. Monitor Operations remnatat the tube bundle from the tank.

3. Receive tube bundle and move to low hackgromal area.

4. Dismantle tuhe hundle and hag surhents for shipment to lahoratory. 


\section{APPENDIX II Bundle A SETTING SYSTEM FLOW RATES}

\section{FOR SUMMA" SAMPLING}

1

1. From Stand-by Mode, open valve V-5, V-6.

2. Ensure valves V-1, V-2, V-3 and V-4 are closed.

3. Without SUMMA" line connected to smmple port 5:

$L_{\text {a. }} \quad$ Turn on sample pump and open valve $V-7$.

6. Adjust rotameter FG-5 to the desired tlow range (usually the 150 mark).

vc. Allow system to purge for the desired time.

3. Close valve V-7, V-5 and V-6.

e. Turn OFF the sample purnp.

4. Connect wire re-enforced teflon line in tube bundle to SUMMA" sample port. $12 i+16$

5. System is operational for SUMMA" sampling.

\section{FQR SORBENT SAMPLING}

1. From Stand-hy Mode, open valves V-1, V-2, V-3, and V-4

2. Ensure valve 6 is closed.

3. With no sample lines contrected to the sample ports:

d. Turn ON the sample pump.

b. Open valve $V-7$

2. O- Op

(1. With the rotameter needle valves (FG-1 throogh FG-4), adjust the flow rate, indicated by the Flowmeter, to the desired flow range.

e. Ensure the totalizers are counting flow volume.

i. Cluse valve V-1, V-2, V-3, V-4 and V-7.

9. Turn OFF the sample pump.

4. System is operattional for sorhent sampling. 
WHC-SD-WM-OTR-196, REV. O

WHC-IP-1127, Sampling and Mobile Laboratories Procedures

4.8

Vapor Sampling of Waste Tanks Using

Rev. 0

In Situ Vapor Sampling System (ISVS)

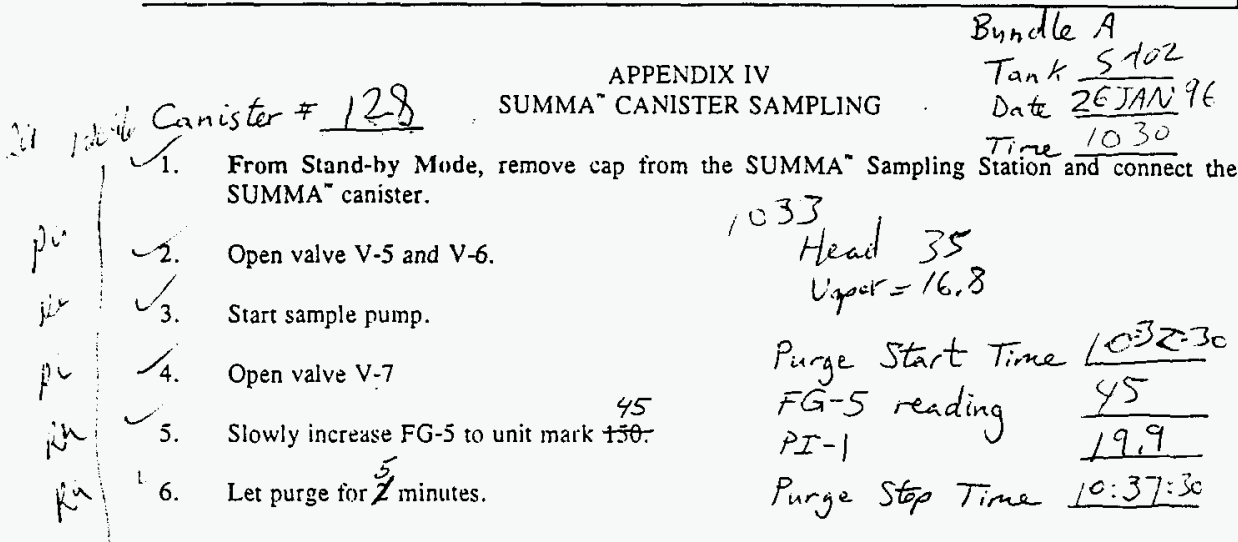

*Periodically check carbonldryrite cylinder tor gross liquid contamination during tank gas purge. Shut down system should this occur.

ic $/ 7$. Close valves $V-6$ and $V-7$.

6. Turn offi sample pump.

th

1 L $/ 9$. Reset Stopwatch

if 10. Simultaneously: Open SUMMA canister valve Start Time 10:57:30

ii A1. Allow 60 seconds for canister to till.

Hui 42 Close the SUMMA* canister valve.

$+2 / 13$. Close valve $V-5$.

2i: T4. Remove the exposed SUMMA" canister and replace SUMMA" station cap or install next SUMMA" sample and repeat procedure at step 2.

i. 15 . Record any anomalies in field notes.

16. Return to standhy mude (Section 8.2).

ifi 
WHC-SD-WH-OTR-196, REN, O

WHC-IP-1127, Sampling and Mobile Laboratories Procedures

4.8

Rev. 0

Vapor Sampling of Waste Tanks Using

May 5, 1995

In Situ Vapor Sampling System (ISVS)

Page 12 of 16

- Bundle $A$

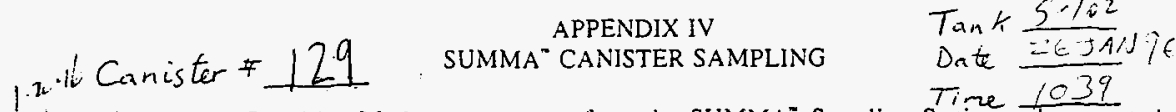

$i^{2}$ 4. From Stand-by Mude, remove cap from the SUMMA" Sampling Station and connect the SUMMA" canister.

12. Open valve V-5 and V-6.

$\mathcal{H}^{2}$. S. Start sample pump.

Ap 4 . Open valve $V-7$

fin : Slowly increase FG-5 to unit mark to.

Pirge Start Time $10 \%$ FG-5 reading

$P I-1$

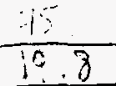

in: ve. Let purge tor 2 minutes.

Pirge Stop Time 1512

*Periodically check carbonldryrite cylinder for gross liquid contamination during tank gas purge. Shut down system should this occur.

wh $/ 7$. Close valves $v-6$ and $V-7$.

$i^{2 n} / 8$. Turn oft sample pump.

in 6 . Reset Stopwatch

$i^{2}$ 10. Simultaneously: Open SUMMA canister valve St, Time $\begin{gathered}\text { Start Stopwatch } \\ \text { St }\end{gathered}$

1iv Allow 60 seconds for canister to till.

ic) - 12 . Close the SUMMA" canister valve.

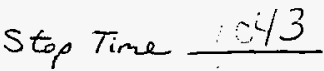

Kh) L 13 . Conse valve V-5.

14 14. Remove the exposed SUMMA" canister and replace SUMMA" station cap or install next SUMMA" sample and repeat prucedure at step 2.

14 Record any anomalies in field notes.

pat

1 ild 16. Return to standhy mode (Section 8.2). 
it T. From Stand-by Mude, remove cap from the SUMMA" Sampling Station and connect the SUMMA" canister.

$f^{n}$ 2. Open valve V-5 and V-6.

in 3. Start sample pump.

in 44 Open valve $v-7$

$\therefore$ S. Slowly increase FG-5 to unit mark t5o.

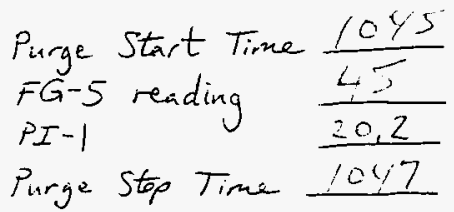

it 16 . Let purge tor 2 minutes.

*Periodically check carbonldryrite cylinder for gross liquid contamination during tank gas purge. Shut down system should this occur.

in . Close valves V-6 and V-7.

k. ᄂ. Turn otfi sample pump.

11/2/9. Reset Stopwatch

i. Limultaneously: Open SUMMA canister valve Start Time 1047

$1^{2} V_{11 .}$ Allow 60 seconds for canister to fill.

1 it 12 . Close the SUMMA- canister valve.

Stop Time 1048

13. Close vilve V-5.

14. Remove the exposed SUMMA" canister and replace SUMMA" station cap or install next SUMMA" sample and repeat procedure at step 2.

15. Record any anomalies in field notes.

16. Return to standhy mode (Section 8.2).

, $26:$ 
WHC-SD-WM-OTR-196, REV. $O$

WHC-IP-1127, Sampling and Mobile Laboratories Procedures

4.8

Rev. 0

Vapor Sampling of Waste Tanks Using

May 5, 1995

In Situ Vapor Sampling System (ISVS)

Page 9 of 16

\section{APPENDIX II \\ SETTING SYSTEM FLOW RATES}

\section{FOR SUMMA" SAMPLING}

1. From Stand-by Mode, open valve $V-5, V-6$.

2. Ensure valves $\mathrm{K}-1, \mathrm{~V}-2, \mathrm{~V}-3$ and $\mathrm{V}-4$ are closed.

3. Without SUMMA" line connected to sample port 5:

a. Turn on sample pump and open valve V-7. 45

b. Adjust rotameter FG-5 to the destral tlow range (usually the 150 mark).

c. Allow system to purge for the desired tixye.

d. Close valve V-7, V-5 and V-6.

e. Turn OFF the sample pump.

4. Connect wire re-enforced teflon line in tube bundle to SUMMA" sample port.

5. System is operational for SUMMA" sampling. i. : "

\section{FOR SORBENT SAMPLING Bundle $A$ PNLTSTS}

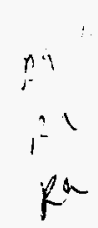

From Stand-hy Mrnde, open valves V-1, V-2, V-3, and V-4

2. Ensure valve $V-6$ is closed.

3. With no sample lines connected to the sample ports:

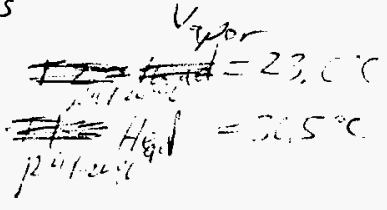

d. Turn ON the sample pump.

- b. Open valve V.7

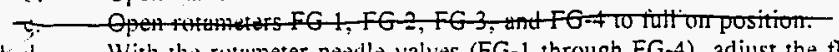

1. With the rutameter needle valves (FG-1 through FG-4), adjust the tlow rate, indicated by the Flowmeter, to the desired flow range. $320 \mathrm{secm}$

- e. Ensure the totalizers are counting flow volume.

$L$ f. Cluse valve V-1, V-2, V-3, V-4 and V-7.

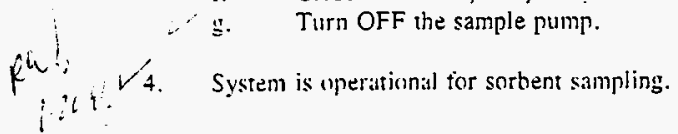


WHC-SD-WM-OTR-196, REV. O

WHC-IP-1127, Sampling and Mobile Laboratories Procedures

4.8

Vapor Sampling of Waste Tanks Using

Rev. 0

In Situ Vapor Sampling System (ISVS)

May 5, 1995

Page 10 of 16

APPENDIX III

Bundle $A T S T$

\section{SORBENT TUBE SAMPLING}

From Stand-by Mode, ensure the cap is on the SUMMA" Sampling Station. Connect wire reenforced teflon line in tube bundle to SUMMA" sample port.

Open valve $\mathrm{V}-5$ and $\mathrm{V}-6$.

Start sample pump.

Open valve V-7

Slowly increase FG-5 to unit mark $\begin{array}{r}45 \\ 50 .\end{array}$

Let purge for 2 minutes. $0>3 \rightarrow 1055$

*Periodically check carbonldryrite cylinder for gross liquid contamination during tank gas purge. Shut down system should this occur.

Close values $V-5, V-6$ and $V-7$.

8. Turn off sample pump.

-6. Attach tube bundle sample lines to the sample ports 1 through 4.

it

i. L 10 .

Second person independently verify correct connections. If any sample port is NOT in use, ensure the respective valve ( $\mathrm{V}-1$ through $\mathrm{V}-4)$ is closed.

$\because$ On the tube bundle upstream of the sample ports, open C-tlex clamps on sample lines in use.

:12. Start sample pump.

Ki "i3. Zero intalizers.

i" Nit. Open Valve V-7.

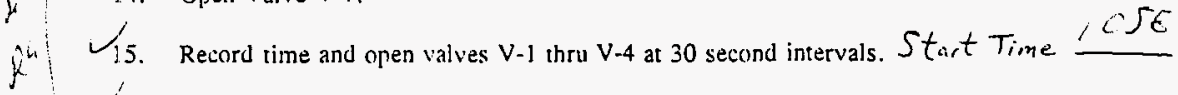

$j^{\text {in }}$ : . Verify all Flowmeters are indicating the desired thow range. Adjust as necessary.

in Lín. Verify Totalizers are cuunting total volume.

in

18. Verify sicila gel tuhes SG-1, SG-2, SG-3 and SG-4 show no liquid contamination.

*Periodically check silica gel for gross liguid contamination during sorbent sampling. Shut down system should this occur. 
WHC-IP-1127, Sampling and Mobile Laboratories Procedures

Vapor Sampling of Waste Tanks Using

Rev. 0

In Situ Vapor Sampling System (ISVS)

19. At elapsed time, 2 minutes, enter into field notes;

a. Flow ràte of each line measured at the corresponding Flowmeter.

b. Temperature of sampling system $T-1, T-2, T-3$ and $T-4$.

c. Internal vacuum indicated at $\mathrm{PI}-1$ in inches of $\mathrm{Hg}$.

d. Any field observations during sampling.

$1^{2} / 20$. During sorbent tube collection enter into field notes;

a. Flow rate of each line measured at the corresponding Flowmeter.

b. Temperature of sampling system $T-1$ and $T-2$.

c. Internal vacuum indicated by $\mathrm{PI}-1$ in inches of $\mathrm{Hg}$.

d. Any field observations during sampling.

1)

L2:

When each totalizer has counted the desired volume-range specified in the TCP, close the

21a. Wait 5 minutes besre clasing $=$-flex clamps and renowing sample lines (step 2y)

22. Close valve $V-7$ and shut off pump.

23. Record sample volumes and actual sample time into field notes.

L' $24 . \quad$ Close C-tlex clamps and remove sample lines from sample ports.

25. Record any anomalies in field notes.

$r^{i}$

26. Return to standhy mode (Section 8.2).

$$
\begin{aligned}
& F T * 1 \frac{205}{205} \\
& F T * 2=207 \\
& F T * 3+4
\end{aligned}
$$


WHC-SO-WM-OTR-196, REV. O

TANK $5-102$

DATE 26 JAN $\%$

TIME 1055

\begin{tabular}{|c|c|c|c|c|}
\hline Sample \# & Port \# & $\begin{array}{c}\text { Start } \\
\text { Time }\end{array}$ & $\begin{array}{c}\text { Stop } \\
\text { Time }\end{array}$ & $\begin{array}{l}\text { Totalizer } \\
\text { Volume }\end{array}$ \\
\hline 817 & 1 & 1056 & & 205 \\
\hline 818 & 2 & 1056 & & 205 \\
\hline 819 & 3 & 1056 & & 207 \\
\hline & 4 & & & \\
\hline
\end{tabular}

\begin{tabular}{|l|l|l|l|l|l|l|l|l|l|}
\hline TIME & FM-1 & FM-2 & FM-3 & FM-4 & T-1 & T-2 & T-3 & T-4 & PI-1 \\
\hline & & & & & & & & & \\
\hline & & & & & & & & & \\
\hline & & & & & & & & & \\
\hline & & & & & & & & & \\
\hline & & & & & & & & & \\
\hline & & & & & & & & & \\
\hline & & & & & & & & & \\
\hline & & & & & & & & & \\
\hline & & & & & & & & & \\
\hline & & & & & & & & & \\
\hline & & & & & & & & & \\
\hline & & & & & & & & & \\
\hline
\end{tabular}


WHC-SD-WM-OTR-196, REV.

WHC-IP-1127, Sampling and Mobile Laboratories Procedures

Vapor Sampling of Waste Tanks Using May 5, 1995

In Situ Vapor Sampling System (ISVS)

Page 9 of 16

\section{APPENDIX II \\ SETTING SYSTEM FLOW RATES}

$\because \cdot$

\section{FQR SUMMA“ SAMPLING}

1. From Stand-by Mode, open valve V-5, V-6.

2. Ensure valves $<, V-2, V-3$ and $V-4$ are closed.

3. Without SUMMA" line comected to sample port 5:

a. Turn on sample pump and opthialve V-7. 45

b. Adjust rotameter FG-5 to the desirentew range (usually the +50 mark).

c. Allow system to purge for the desired time.

d. Close valve V-7, V-5 and V-6.

e. Turn OFF the sample pump.

4. Connect wire re-enforced teflon line in tube bundle to SUMMA" samplepart.

5. System is operational for SUMMA" sampling.

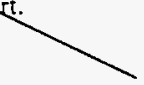

\section{FOR SORBENT SAMPLING Bundle $\mathrm{A} \quad \mathrm{NH}_{3} / \mathrm{H}_{2} \mathrm{O}$}

(s) 1 . From Stand-hy Mode, open valves $V-1, V-2, V-3$, and $V-4$

$j$

$\because \quad-2$. Ensure valve V-6 is closed.

i

A.) L. 3. With no sample lines connected to the sample ports:

c. Turn ON the sample pump.

फ. Open valve V-7

$\tau$ T-Open

d. With the rotameter needle valves (FG-1 through FG-4), adjust the tlow rate, indicated by the Flowmeter, to the desired tlow range. $220 \mathrm{sccm}$

E. Ensure the totalizers are counting tlow volume.

f. Cluse valve V-1, V-2, V-3, V-4 and V-7.

\&. Turn OFF the sample pump.

a System is uperational for sorbent sampling. 


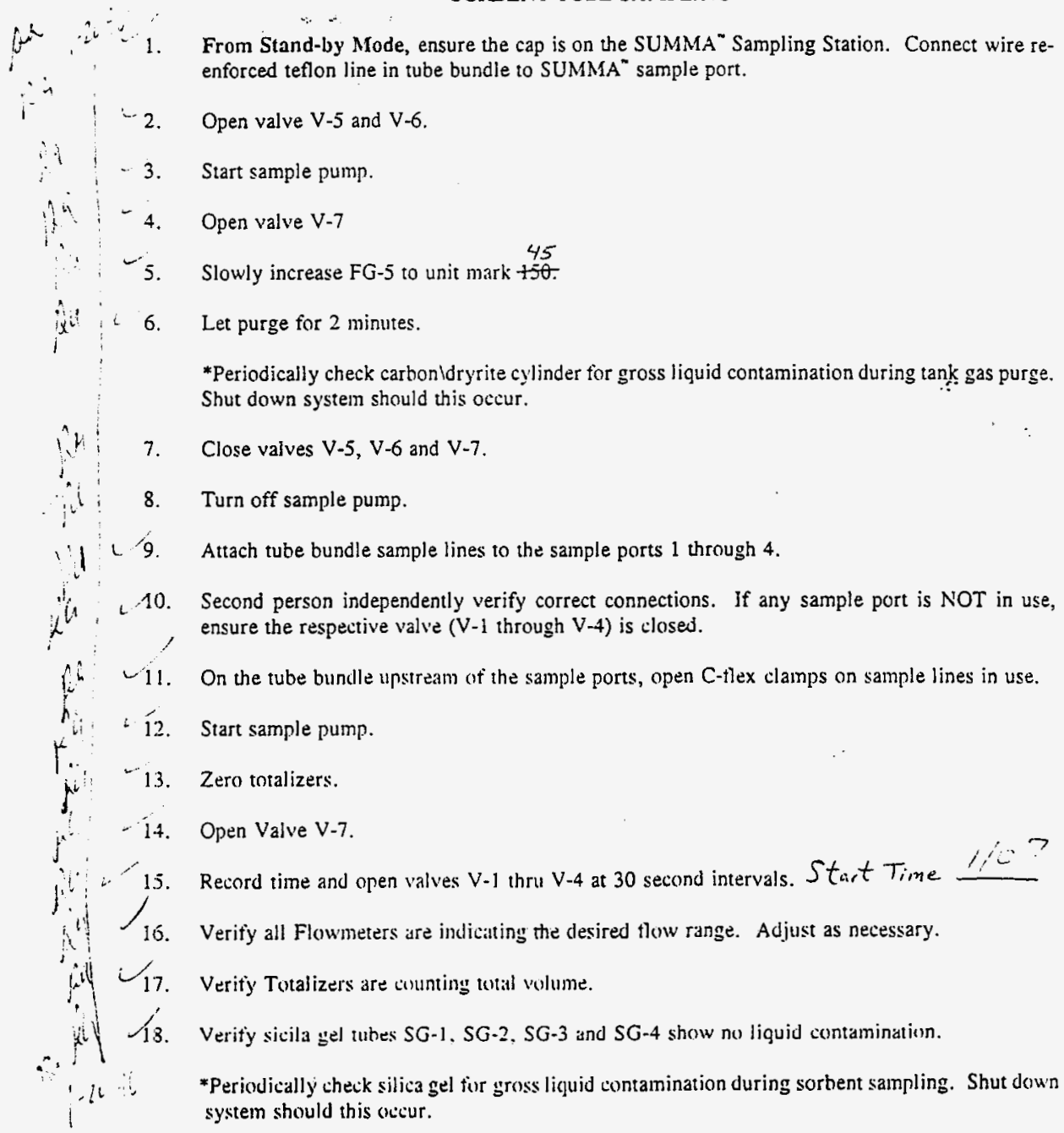


Vapor Sampling of Waste Tanks Using

15. At elapsed time, 2 minutes, enter into field notes;
a. Flow ràte of each line measured at the corresponding Flowmeter.
b. Temperature of sampling system $T-1, T-2, T-3$ and $T-4$.
c. Internal vacuum indicated at $\mathrm{Pl}-1$ in inches of $\mathrm{Hg}$.
d. Any field observations during sampling.

20 . During sorbent tuhe collection enter into field notes;
a. Flow rate of each line measured at the corresponding Flowmeter.
b. Temperature of sampling system T-1 and T-2.
c. Internal vacuum indicated by $\mathrm{PI}-1$ in inches of $\mathrm{Hg}$.
d. Any field observations during sampling.

$\therefore \quad-21$

When each totalizer has counted the desired volume-range specified in the TCP, close the

$\because \because \quad$ appropriate valve V-1 through V-4.

V́19. Wait 5 minutes batre clusing

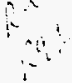

22. Close valve V-7 and shut off pump.

23. Record sample volumes and actual sample time into field notes.

24. Close C-flex clamps and remove sample lines from sample ports.

25. Record any anomalies in field notes.

26. Return to standhy mode (Section 8.2).

$$
\begin{aligned}
\text { Time } & =\frac{1122}{\text { Head }}=26.9^{\circ} \mathrm{C}
\end{aligned}
$$

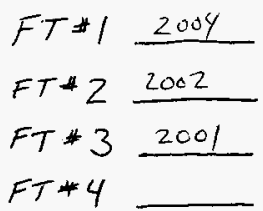

FTH 2002

$F T * 3$ 2001

$F T+4$ 
WHC-SO-WM-OTR-196, REV. O

TANK $5-102$

DATE $263 \pi / 76$

TIME $\Perp 09$

\begin{tabular}{|c|c|c|c|c|}
\hline Sample \# & Port \# & $\begin{array}{l}\text { Start } \\
\text { Time }\end{array}$ & $\begin{array}{c}\text { Stop } \\
\text { Time }\end{array}$ & $\begin{array}{l}\text { Totalizer } \\
\text { Volume }\end{array}$ \\
\hline 80,5 & 1 & 1107 & & 2004 \\
\hline $81 S$ & 2 & 110730 & & 2002 \\
\hline 82.5 & 3 & 1108 & & 2001 \\
\hline & 4 & & & \\
\hline
\end{tabular}

Tank Vapor

\begin{tabular}{|c|c|c|c|c|c|c|c|c|c|}
\hline TIME & FM-1 & FM-2 & FM-3 & FM-4 & $T-1$ & $\mathrm{~T}-2$ & $T-3$ & $T-4$ & $\mathrm{PI} \mid-1$ \\
\hline $11-9\}$ & $\therefore 6$ & $2 / 6$ & $\therefore / 6$ & $\hat{i}$ & 2,5 & 24 & 28 & 1 & 21 \\
\hline 1114 & 219 & $2 \mathrm{zl}$ & 219 & $e$ & 3.5 & 24.8 & & & \\
\hline & & & & & & & & & \\
\hline & & & & & & & & & \\
\hline & & & & & & & & & \\
\hline & & & & & & & & & \\
\hline & & & & & & & & & \\
\hline & & & & & & & & & \\
\hline & & & & & & & & & \\
\hline & & & & & & & & & \\
\hline & & & & & & & & & \\
\hline & & & & & & & & & \\
\hline & & & & & & & & & \\
\hline & & & & & & & & & \\
\hline & & & & & & & & & \\
\hline
\end{tabular}

$11 / 2$ jample Head $=27.7$ 


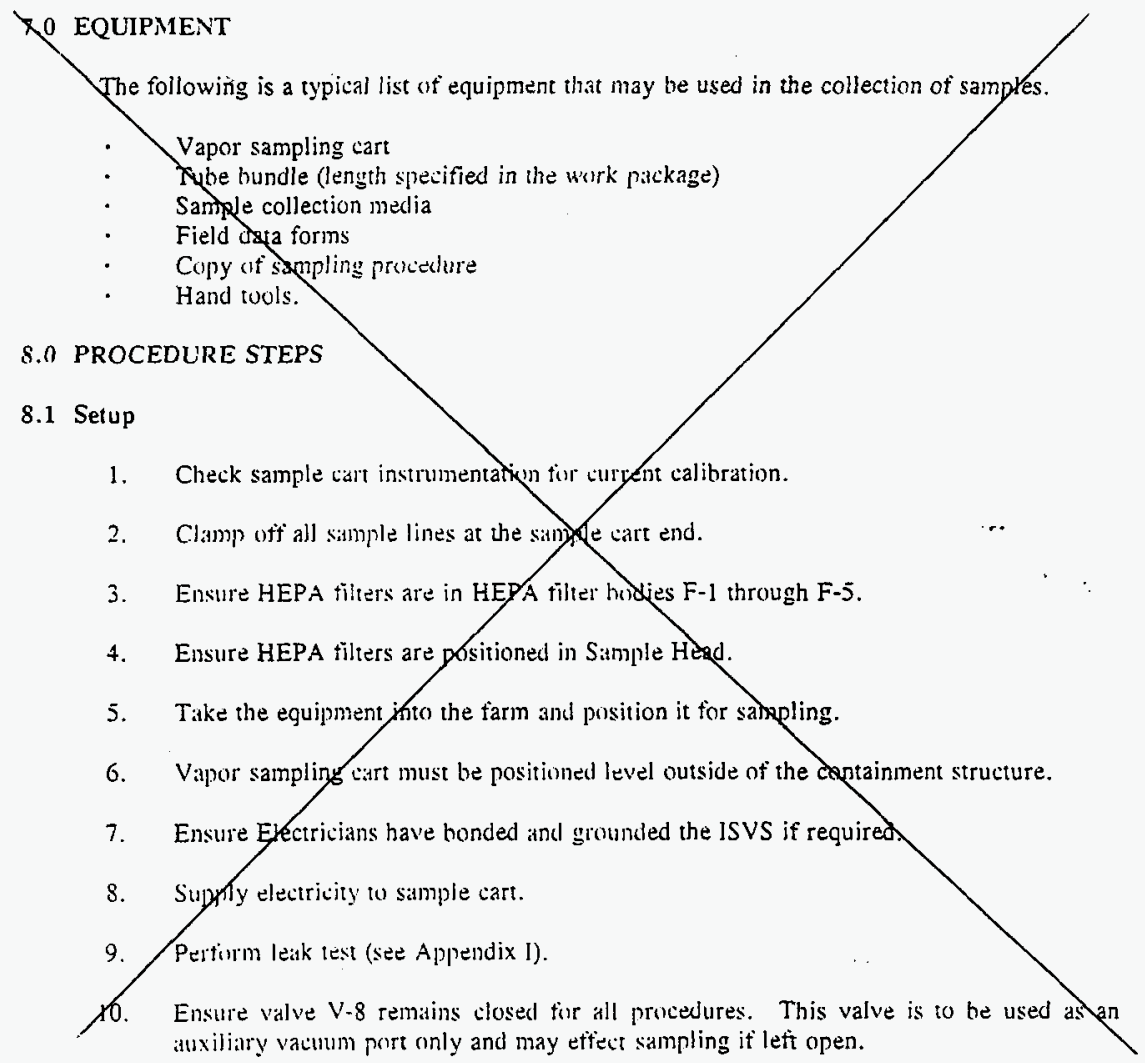
auxiliary vacuum port only and may effect sampling if left open.

\section{S.1.1 Tube Bundle Plincement}

\section{Insert Bundle B}

- NOTE: The tule bundle is still under COC and the responsibility of the sampling team. It is essential that it he visually munitured throughout the insertion into lle lank and during removal.

1. If simpling from ventilation duet with a pitot tuhe, see Appendix VI. If not, proceed wo step?.

2. Supply the tuhe hunde ou the Operations PIC. 
3. Monitor the placement of the tube bundle in the containment structure.

4. Monitor the tube bundle during insertion to ensure Operations placement at the correct depth/location, per TCP instructions.

5. In the field notes, record the;

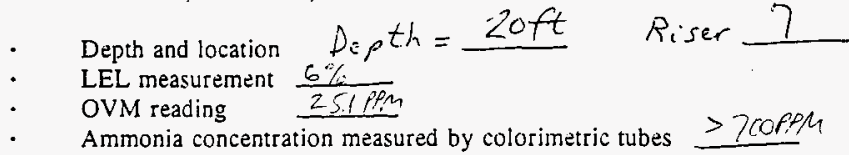

- Any anomalies associated with setur.

\subsection{Standby Mode}

L1. During the standby mode the sample cart shall be ready for operation and in the following contiguration:

2. Tube bundle is in the sampling position/location in the tank but not connected to the cart.

5. Valves $V-1, V-2, V-3, V-4, V-5, V-6$ and $V-7$ are closed.

e. Sample pump is off.

đ. Power is on to the flowmeters and totallizers

2. The standby mode serves as a reference point from which the following functions can be .. performed.

\begin{tabular}{|l|c|}
\hline \multicolumn{1}{|c|}{ Description } & Appendix \\
\hline Leak: Test & I \\
\hline Setting System Flow Rates & II \\
\hline Sorbent Tube Sampling & IIl \\
\hline SUMMA* Canister Sampling & IV \\
\hline Flow-Through Cylinder Sampling & V \\
\hline
\end{tabular}

\section{-8.3 Shutdown}

1. Requas HPT coverage during steps 2 through 6.

2. Monitor Operations relnowal of the tube hundle from the tank.

3. Receive tube bundle and move to low backgreund area.

4. Dismantle tuhe hundle and bag sorhents for shipment to lahoratmex 


\section{APPENDIX II} $\because$ SETTING SYSTEM FLOW RATES

\section{FOR SUMMA" SAMPLING}

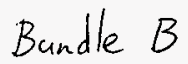

1. From Stand-by Mode, open valve V-5, V-6.

2. Ensure valves $V-1, V-2, V-3$ and $V-4$ are closed.

3. Without SUMMA" line connected to sample port 5:

2. Turn on sample pump and open valve $V-7$.

Adjust rotameter FG.5 to the desired thow range (usually the 150 mark).

c. Allow system to purge for the desired time.

C. Close valve V-7, V-5 and V-6.

e. Turn OFF the sample pump.

4. Connect wire re-enforced tetion line in tube bundle to SUMMA" sample port.

5. System is operational for SUMMA* sampling.

\section{FQR SORBENT SAMPLING}

1.

From Stand-hy Mode, open valves V-1, V-2, V-3, and V-4

2. Ensure valve -6 is closed.

3. With no sample lines connected to the sample ports:

a. Turn ON the sample punes.

b. Open valve V-7

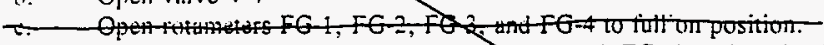

d. With the rotameter needle valves ( $F G-x$ through $F G-4$ ), adjust the flow rate, indicated by the Fluwmeter, to the desired flow range.

e. Ensure the totalizers are counting thow volume.

f. Close valve $V-1, v-2, v-3, V-4$ and $V-7$.

y. Turn OFF the sample pump.

4. System is uperational for sorbent sampling. 


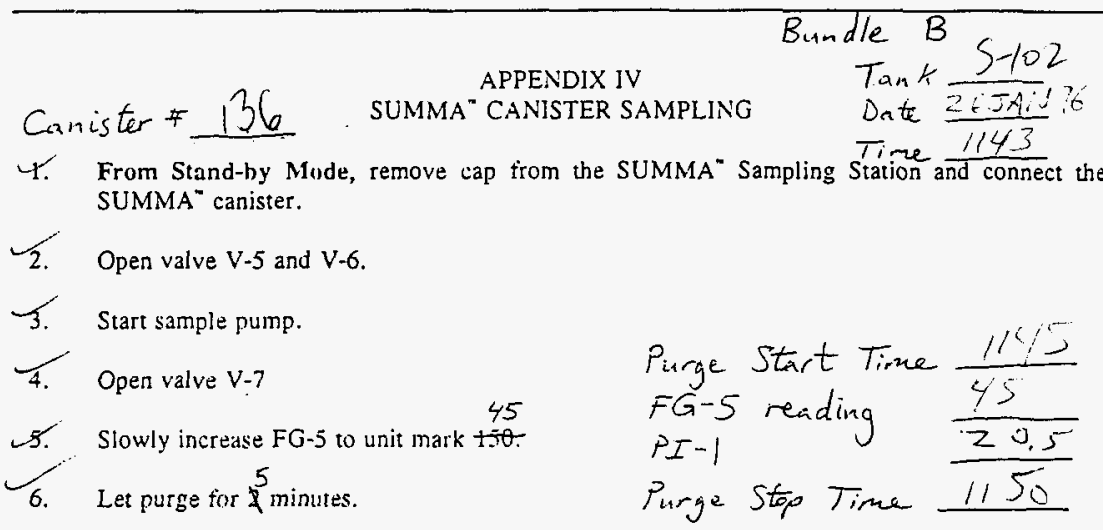

*Periodically check carbonldryrite cylinder for gross liquid contamination during tank gas purge. Shut down system should this ociur.

7. Close valves $v-6$ and $v-7$.

V. Turn otit sample pump.

9. Reset Stopwatch

10. Simultaneously: Open SUMMA canister valve Start Time. 1150 Start Stopwatch

t1. Allow 60 secunds for canister to fill.

112. Close the SUMMA canister valve. Stop Time 1151

13. Cluse valve $v-5$.

C14. Remove the exposed SUMMA" canister and replace SUMMA" station cap or install next SUMMA* sample and repeat procedure at step 2.

15. Record any anomalies in field notes.

16. Rerurn to stanuhy mode (Section 8.2). 
WHC-SD-WM-OTR-196, REV, O

WHC-IP-1127, Sampling and Mobile Laboratories Procedures

4.8

Rev. 0

Vapor Sampling of Waste Tanks Using

May 5, 1995

In Situ Vapor Sampling System (ISVS)

Page 12 of 16

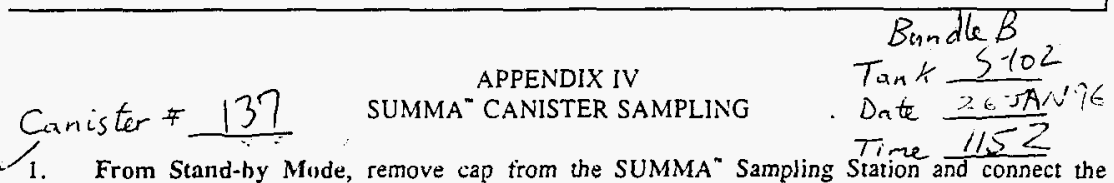
SUMMA" canister.

2. Open value $V-5$ and $V-6$.

3. Start sample puinp.

4. Open valve V-7

5. Slowly increase FG-5 to unit mark t50.

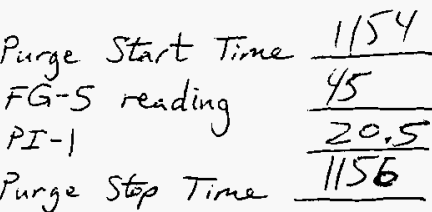

6. Let purge for 2 minutes.

Purge Stop Time 1156

*Periodically check carbonldryrite cylinder for gross liquid contamination during tank gas purge. Shut down system should this occur.

7. Close valves $\mathrm{V}-6$ and $\mathrm{V}-7$.

8. Turn off sample pump.

9. Reset Stopwatch

10. Simultaneously: Open SUMMA canister valve s.tart Time 1156 Start Stopwatch

11. Allow 60 seconds for canister to fill.

12. Close the SUMMA" canister valve.

Stop Time 1157

13. Clise valve $V-5$.

14. Remove the exposed SUMMA" canister and replace SUMMA" station cap or install next SUMMA“ sample und repeat procedure at step 2 .

15. Record any anomalies in tield notes.

16. Return to standhy inude (Section 8.2). 
WHC-SD-WM-OTR-196, REV.

WHC-IP-1127, Sampling and Mobile Laboratories Procedures

4.8

Rev. 0

Vapor Sampling of Waste Tanks Using

May 5, 1995

In Situ Vapor Sampling System (ISVS)

Page 12 of 16

Bundle $B$

Canister $* 153$ SUMMA" CANISTER SAMPLING

Tank $\frac{5-102}{5-71}$

i. From Stand-by Mude, remove cap from the SUMMA* Sampling Station and connect the SUMMA" canister.

$2 / 2$. Open valve V-5 and V-6.

3. Start sample pump.

4. Open valve $V-7$

S. Slowly increase FG-5 to unit mark t50.

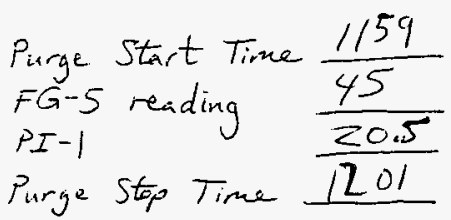

6. Let purge for 2 minutes.

Purge Stop Time 1201

*Periodically check carbonldryrite cylinder for gross liquid contamination during tank gas purge.

Shut down system should this occur.

ᄂ. Close valves V-6 and V-7.

8. Turn off sample puinp.

f. Reset Stopwaich

10. Simultaneously: Open SUMMA canister valve Start Time 1201 Start Stopwatch

-11. Allow 60 seconds for canister to fill.

12. Close the SUMMA" canister valve.

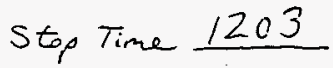

/3. Close vilve $v-5$.

14. Remove the exposed SUMMA" canister and replace SUMMA" station cap or install next SUMMA" sample and repeat procedure at step $?$.

15. Retord any anomalies in field notes.

16. Return to standhy mode (Section 8.2). 
WHC-SD-WM-OTR-196, REV. O

WHC-IP-1127, Sampling and Mobile Laboratories Procedures

Vapor Sampling of Waste Tanks Using

\section{APPENDIX II \\ SETTING SYSTEM FLOW RATES}

\section{FOR SUMMA" SAMPLING}

1. From Sland-hy Mode, open valve V-5, V-6.

2. Ensure valvex $\mathrm{V}-1, \mathrm{~V}-2, \mathrm{~V}-3$ and $\mathrm{V}-4$ are closed.

3. Without SUMMA" linecennected to sample port 5:

a. Turn on sample pump anthenen valve V-7.

b. Adjust rotameter FG.5 to the dxired tlow range (usually the 150 mark).

c. Allow system to purge for the desinuctime.

d. Close valve V-7, V-5 and V-6.

e. Turn OFF the sample pump.

4. Connect wire re-enforced tetlon line in tube bundle to SUMMAN sample port.

5. System is operational for SUMMA" sampling.

\section{FOR SORBENT SAMPLING Bundle B TSTs}

1. From Stand-hy Mode, open valves $V-1, V-2, V-3$, and $V-4$

2. Ensure valve $V-6$ is closed.

3. With no sample lines connected to the sample ports:

16. Turn ON the sample pump.

Y. OP.

d. With the rotameter needle valves (FG-1 through FG-4), adjust the flow rate, indicated

f hy the Flowmeter, to the desired tlow range. $3205 \mathrm{ccm}$

e. Ensure the totalizers are counting flow volume.

Cluse valve $V-1, V-2, v-3, V-4$ and $V-7$.

g. Turn OFF the sample pump.

4. '́system is uperational for sorbent sampling. 
APPENDIX III

\section{SORBENT TUBE SAMPLING}

1. From Stand-by Mode, ensure the cap is on the SUMMA" Sampling Station. Connect wire reenforced tefion line in tube bundle to SUMMA" sample port.

2. Open valve $\mathrm{V}-5$ and $\mathrm{V}-6$.

3. Start sample pump.

4. Open valve V-7

5. Slowly increase FG-5 to unit mark +45

6. Let purge for 2 minutes.

*Periodically check carbonldryrite cylinder for gross liquid contamination during tank gas purge. Shut down system should this occur.

$\sqrt{7}$. Close valves $\mathrm{V}-5, \mathrm{~V}-6$ and $\mathrm{V}-7$.

8. Turn off sample pump.

ब. Attach tube bundie sample lines to the sample ports 1 through 4 .

10. Second person independently verify correct connections. If any sample port is NOT in use, ensure the respective valve (V-1 through $V-4)$ is closed.

11. On the tube bundle upstream of the sample ports, open C-tlex clamps on sample lines in use.

42. Start sample pump.

- Y3. Zero totalizers.

14. Open Valve V-7.

15. Record time and open valves $v-1$ thru $V-4$ at 30 second intervals. Start Time 120,8

16. Verify all Flowmeters are indicating the desired flow range. Adjust as necessary.

17. Verify Totalizers are Lumning total volume.

18. Verify sicila gel tubes SG-1, SG-2, SG-3 and SG-4 show no liquid contamination.

*Periodically check silica gel fior gross liquid contamination during sorbent sampling. Shut down system should this occur. 
WHC-SO-WM-OTR-196, REV. O

WHC-IP-1127, Sampling and Mobile Laboratories Procedures

4.8

Vapor Sampling of Waste Tanks Using

Rev. 0

In Situ Vapor Sampling System (ISVS)

May 5, 1995

Page 11 of 16

19. At elapsed time, 2 minutes, enter into field notes;

a. Flow räte of each line measured at the corresponding Flowmeter.

b. Temperature of sampling system $T-1, T-2, T-3$ and $T-4$.

c. Internal vacuum indicated at $\mathrm{PI}-1$ in inches of $\mathrm{Hg}$.

d. Any field observations during sampling.

20. During sorbent tube collection enter into field notes;

a. Flow rate of each line measured at the corresponding Flowmeter.

b. Temperature of sampling system $T-1$ and $T-2$.

i. Internal vacuum indicated by $\mathrm{Pl}-1$ in inches of $\mathrm{Hg}$.

d. Any field observations during sampling.

21. When each totalizer has counted the desired volume-range specitied in the TCP, close the appropriate valve V-1 through V-4.

2la. Wait 5 minutes besie clesing

-22. Close valve V-7 and shut off pump.

23. Record sample volumes and actual sample time into field notes.

24. Close C-tlex clamps and remove sample lines from sample ports.

25. Record any anomalies in field notes.

26. Return to standby mode (Section 8.2).

$$
\begin{aligned}
& F T * 1 \frac{205}{203} \\
& F T * 2 \frac{203}{F T * 3} \\
& F T * 4
\end{aligned}
$$


TANK $5-102$

DATE $=\epsilon$ JAN 96

TIME 1207

\begin{tabular}{|c|c|c|c|c|}
\hline Sample \# & Port \# & $\begin{array}{c}\text { Start } \\
\text { Time }\end{array}$ & $\begin{array}{c}\text { Stop } \\
\text { Time }\end{array}$ & $\begin{array}{c}\text { Totalizer } \\
\text { Volume }\end{array}$ \\
\hline 821 & 1 & 1208 & & 205 \\
\hline 822 & 2 & 1208 & & 203 \\
\hline 423 & 3 & 1208 & & 203 \\
\hline & 4 & & & \\
\hline
\end{tabular}

\begin{tabular}{|c|c|c|c|c|c|c|c|c|c|}
\hline TIME & FM-1 & FM-2 & FM-3 & FM-4 & T-1 & T-2 & T-3 & T-4 & PI-1 \\
\hline & & & & & & & & & \\
\hline & & & & & & & & & \\
\hline & & & & & & & & & \\
\hline & & & & & & & & & \\
\hline & & & & & & & & & \\
\hline & & & & & & & & & \\
\hline & & & & & & & & & \\
\hline & & & & & & & & & \\
\hline & & & & & & & & & \\
\hline & & & & & & & & & \\
\hline & & & & & & & & & \\
\hline & & & & & & & & & \\
\hline
\end{tabular}


APPENDIX II

SETTING SYSTEM FLOW RATES

\section{EOR SUMMA" SAMPLING}

1. From Stand-by Mode, open valve V-5, V-6.

2. Ensure valvex V-1, V-2, V-3 and V-4 are closed.

3. Without SUMMA" lineconnected to sample port 5:

a. Turn on sample pump and open valve V-7. 45

b. Adjust rotameter FG-5 to the ssired tlow range (usually the 150 mark).

c. Allow system to purge for the destred time.

d. Close valve V-7, V-5 and V-6.

e. Turn OFF the sample pump.

4. Connect wire re-enforced teflon line in tube bundle to SUMMX- sample port.

5. System is operational for SUMMA" sampling.

\section{FOR SORBENT SAMPLING Bundle $\mathrm{B} \quad \mathrm{NH}_{3} / \mathrm{H}_{2} \mathrm{O}$}

1. From Stand-hy Mfode, open valves $V-1, V-2, V-3$, and $V-4$

ᄂ2. Ensure value $V-6$ is closed.

3. With no sample lines connected to the sample ports:

a. Turn ON the sample pump.

b. Open vilve V-7

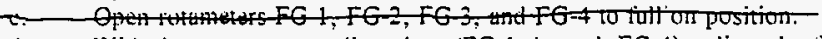

d. With the rotameter needle valves (FG-1 through FG-4), adjust the flow rate, indicated by the Flowmeter, to the desired tlow range. $2205 \mathrm{ccm}$

$\checkmark$ e. Ensure the totalizers are counting flow volume.

i. Close valve V-1, V-2, V-3, V-4 and V-7.

g. Turn OFF the sample pump.

$\checkmark$ 4. System is uperational for sorbent sampling. 


\section{APPENDIX III

4 . From Stand-by Mode, ensure the cap is on the SUMMA Sampling Station. Connect wire reenforced teflon line in tube bundle to SUMMA" sample port.

2. Open valve $\mathrm{V}-5$ and $\mathrm{V}-6$.

3. Start sample pump.

4. Open valve V-7

3. Slowly increase FG-5 to unit mark +50

Let purge for 2 minutes.

*Periodically check carbonldryrite cylinder for gross liquid contamination during tank gas purge. Shut down system should this occur.

7. Close valves $V-5, V-6$ and $V-7$.

8. Turn off sample pump.

9. Attach tube bundle sample lines to the sample ports 1 through 4 .

10. Second person independently verify correct connections. If any sample port is NOT in use, ensure the respective valve ( $V-1$ through $V-4)$ is closed.

11. On the tube bundle upstream of the sample ports, open C-tlex clamps on sample lines in use.

L12. Start sample pump.

13. Zero totalizers.

14. Open Valve V-7.

$v_{15}^{\prime}$ Record time and open valves $v-1$ thru $v-4$ at 30 second intervals. Sturt Time 1220

16. Verify all Flowmeters are indicating the desired flow range. Adjust as necessary.

17. Verify Totalizers are simnting tot:al volume.

18. Verify sicila gel tuhes SG-1, SG-2, SG-3 and SG-4 show no liquid contamination.

*Periodically check silica gel for gross liguid contamination during sorbent sampling. Shut down system should this occur. 
19. At elapsed time, 2 minutes, enter into field notes;

a. Flow ràte of each line measured at the corresponding Flowmeter.

b. Temperature of sampling system $T-1, T-2, T-3$ and $T-4$.

c. Internal vacuum indicated at PI- 1 in inches of $\mathrm{Hg}$.

d. Any field ohservations during sampling.

$\sqrt{20}$. During sorbent tube collection enter into field notes;

a. Flow rate of each line measured at the corresponding Flowmeter.

b. Temperature of sampling system $T-1$ and $T-2$.

c. Internal vacuum indicated by $\mathrm{PI}-1$ in inches of $\mathrm{Hg}$.

d. Any tield observations during sampling.

21. When each totalizer has counted the desired volume-range specified in the TCP, close the

2la. Wait 5 minutes hosie clusing $\Sigma-$-flex clamps and remoring jample lines (step 24)

22. Close valve $V-7$ and shut off pump.

23. Record sample volumes and actual sample time into field notes.

24. Close C-tlex clamps and remove sample lines from sample ports.

25. Record any anomalies in field notes.

26. Return to standhy mode (Section 8.2).

$$
\begin{aligned}
& F T * 1 \quad 2003 \\
& F T \# 2 \underline{2001} \\
& F T * 32001 \\
& F T+4
\end{aligned}
$$


TANK $5-102$

DATE ZE 2 AN,

TIME 1220

\begin{tabular}{|c|c|c|c|c|}
\hline Sample \# & Port \# & $\begin{array}{c}\text { Start } \\
\text { Time }\end{array}$ & $\begin{array}{c}\text { Stop } \\
\text { Time }\end{array}$ & $\begin{array}{c}\text { Totalizer } \\
\text { Volume }\end{array}$ \\
\hline 835 & 1 & 1220 & & 2003 \\
\hline $84 S$ & 2 & 122030 & & 2001 \\
\hline 855 & 3 & 1221 & & 2001 \\
\hline & 4 & & & \\
\hline
\end{tabular}

\begin{tabular}{|c|c|c|c|c|c|c|c|c|c|}
\hline T.JME & FM-1 & FM-2 & FM-3 & FM-4 & T-1 & T-2 & T-3 & T-4 & PI-1 \\
\hline 1223 & 218 & 220 & $2 / 3$ & 8 & $-0,5$ & 25,4 & 25 & 2 & 21,2 \\
\hline & & & & & & & & & \\
\hline & & & & & & & & & \\
\hline & & & & & & & & & \\
\hline & & & & & & & & & \\
\hline & & & & & & & & & \\
\hline & & & & & & & & & \\
\hline & & & & & & & & & \\
\hline & & & & & & & & & \\
\hline & & & & & & & & & \\
\hline & & & & & & & & & \\
\hline & & & & & & & & & \\
\hline & & & & & & & & & \\
\hline & & & & & & & & & \\
\hline
\end{tabular}

1226 hrs $=$ Head $=28^{\circ} \mathrm{C}$ 
WHC-SD-WM-OTR-196, REV.

WHC-IP-1127, Sampling and Mobile Laboratories Procedures

Vapor Sampling of Waste Tunks Using

\section{T. EQUIPMENT}

The following is a typical list of equipment that may be used in the collection of samples.

- Vapor sampling cart

- Tute bundle (length specified in the wurk pickage)

- Samplacollection media

- Field dataforms

- Copy of sampling procedure

- Hand tools.

\subsection{PROCEDURE STEPS}

\section{1: Selup}

1. Check sample cart instrumentation tive curreft calibration.

2. Clamp off all sample lines at the sampre date end.

3. Ensure HEPA filters are in HEPA filter budies through F-5.

4. Ensure HEPA filters are persitioned in Sanple Head.

5. Take the equipment jorto the farm and position it for sampling.

6. Vapor sampliny cart must be positioned level outside of the containgent structure.

7. Ensure Electricians have honded and grounded the ISVS if required.

8. Supply electricity to sample cart.

9. Pertirm leak test (see Appendix I).

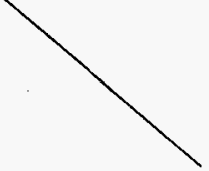

10. Ensure valve V-8 remains closed fur all procedures. This valve is to be used as an atuxiliary vacum port only and may effect sampling it lett open.

\subsubsection{Tube Bundle Plicement}

\section{Insert Bundle C}

NOTE: The tule bundle is still under COC and the responsihility of the sanpling team. It is essential that it he visually monitored throughout the insertion intu llet tank and during renuval.

$\mathcal{J}$ 1. Jf s:ampling from ventilition duct with a pitot tuhe, see Appendix VI. If not, proceed to step 2.

2. Supply the tuhe hundle to the Operations PIC. 
- 3. Monitor the placement of the tube bundle in the containment structure.

4. Monitor the tube bundle during insertion to ensure Operations placement at the correct depth/location, per TCP instructions.

-5. In the field notes, record the;
- Depth and location
Depth $=20 \mathrm{ft}$
Riser 7
- LEL measurement $6 \%$
- OVM reading $\underline{25.1 P p r}$
- Ammonia concentration measured by colorimetric tubes $>700 \mathrm{fPM}$
- Any anomalies associated with setup.

\subsection{Standby Mode}

1. During the standby mode the sample cart shall be ready for operation and in the following contiguration:

a. Tube bundle is in the sampling position/location in the tank but not connected to the cart.

-b. Valves V-1, V-2, V-3, V-4, V-5, V-6 and V-7 are closed.

-c. Sample pump is off.

d. Power is on to the flowmeters and totallizers

2. The standby mode serves as a reference point from which the following tunctions can be .. performed.

\begin{tabular}{||l|c|}
\hline \multicolumn{1}{|c|}{ Description } & Appendix \\
\hline Leak Test & I \\
\hline Setting System Flow Rates & II \\
\hline Sorbent Tube Sampling & III \\
\hline SUMMA- Canister Sampling & IV \\
\hline Flow-Through Cylinder Sampling & V \\
\hline
\end{tabular}

\section{Shutdown}

1. Riquest HPT coverage during steps 2 through 6 .

2. Monitor Operattoss removal of the tuhe bundle from the tunk.

3. Receive tube bundle and move torkew hackground area.

4. Dismantle tube bundle and haig surbents fiur shiptout tu lathoratory. 


\section{APPENDIX II \\ SETTING SYSTEM FLOW RATES}

$\therefore$

\section{FOR SUMMA" SAMPLING Bundle $C$}

1. From Stand-by Mode, open valve V-5, V-6.

2. Ensure valves $V-1, V-2, V-3$ and $V-4$ are closed.

3. Without SUMMA" line connected to sample port 5 :

a. Turn on sample pump and open valve $V-7$. 45

- b. Adjust rotameter FG-5 to the desired tlow range (usually the 150 mark).

$\checkmark$ A. Allow system to purge for the desired time.

d. Close valve V-7, V-5 and V-6.

e. Turn OFF the sample pump.

4. Connect wire re-enforced teflon line in tube bundle to SUMMA- sample port.

5. System is operational for SUMMA" sampling.

\section{FQR SORBENT SAMPLING}

1. From Stand-by Mode, open valves V-1,V-2, V-3, and V-4

2. Ensure valve Drais closed.

3. With no sample lines connected to the sample ports:

a. Turn ON the sample pump.

b. Open valve V.7

t. Op

l. Wirh the rotameter needle valves (FG-1 throtgh FG-4), adjust the flow rate, indicated by the Fluwmeter, to the desired tlow range.

e. Ensure the totalizers are counting flow volume.

t. Cluse valve V-1, V-2, V-3, V-4 and V-7.

g. Turn OFF the sample pump.

4. System is operational for sorbent sampling- 


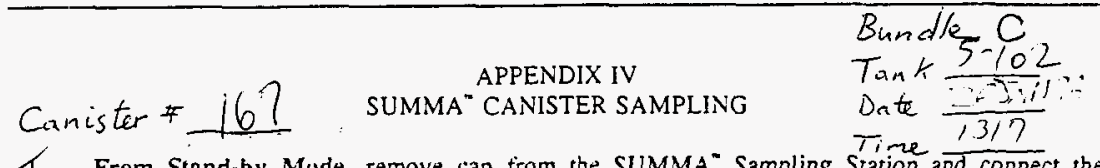

1. From Stand-hy Mude, remove cap from the SUMMA* Sampling Station and connect the SUMMA" canister.

2. Open valve $V-5$ and $V-6$.

3. Start sample pump.

4. Open valve V-7

45

5. Slowly increase FG-5 to unit mark t50.

6. Let purge for $2^{5}$ minutes.

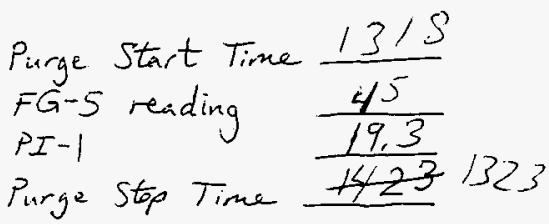

*Periodically check carbonldryrite cylinder for gross liquid contamination during tank gas purge. Shut down system should this occur.

c. Close valves V-6 and V-7.

8. Turn oft sample pump.

9. Reset Stopwatch

10. Simultaneously: Open SUMMA canister valve Start Time 1323 Start Stopwatch

11. Allow 60 seconds for canister to till.

12. Close the SUMMA" canister valve.

Stop Time 1324

13. Cluse valve $V-5$.

14. Remove the exposed SUMMA" canister and replace SUMMA" station cap or install next SUMMA" sample and repeat procedure at step 2.

L15. Record any anomalies in field notes.

16. Return to standhy mode (Section 8.2). 
WHC-SD-WM-OTR-196, REV. O

WHC-IP-1127, Sampling and Mobile Laboratories Procedures

Rev. 0

Vapor Sampling of Waste Tanks Using

May 5, 1995

In Situ Vapor Sampling System (ISVS)

Page 12 of 16

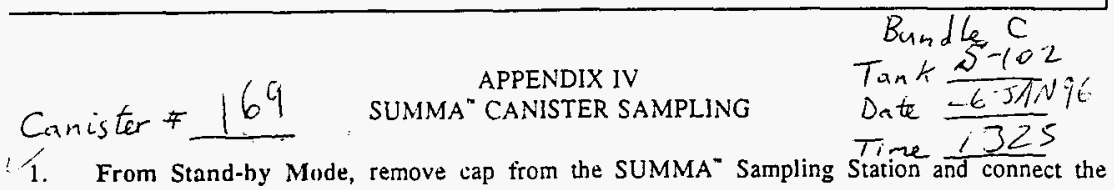
SUMMA" canister.

L 2 . Open valve $V-5$ and $V-6$.

1/3. Start sample puinp.

4. Open valve $\mathrm{V}-7$

$\checkmark$. 45

5. Slowly increase FG-5 to unit mark t50.

6. Let purge for 2 minutes.

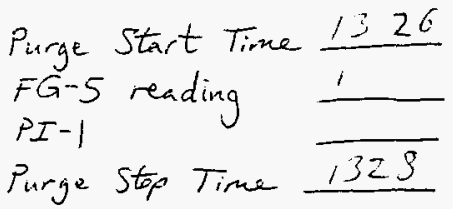

*Periodically check carbonldryrite cylinder for gross liquid contamination during tank gas purge. Shut down system should this occur.

7. Close valves $\mathrm{V}-6$ and $\mathrm{V}-7$.

8. Turn off sample pump.

/9. Reset Stopwatch

- 10. Simultaneously: Open SUMMA canister valve SEart Time 1528 Start Stopwatch

-11. Allow 60 seconds for canister to fill.

12. Close the SUMMA" canister valve. Stop Time 1329

13. Close valve V-5.

14. Remove the exposed SUMMA" canister and replace SUMMA" station cap or install next SUMMA" sample and repeat procedure at step 2.

15. Record any anomalies in tield notes.

16. Return to stanclhy mode (Section 8.2). 
WHC-SD-WM-OTR-196, REV.

WHC-IP-1127, Sampling and Mobile Laboratories Procedures

Rev. 0

Vapor Sampling of Waste Tanks Using

May 5, 1995

In Situ Vapor Sampling System (ISVS)

Page 12 of 16

Bundle C

Tank $5 \% 2$

Canister ${ }^{*} 170$ SUMMA* CANISTER SAMPLING

APPENDIX IV

1. From Stand-hy Mude, remove cap from the SUMMA- Sampling Time $\frac{1330}{30}$ SUMMA" canister.

2. Open valve $V-5$ and $V-6$.

3. Start sample pump.

4. Open valve $v-7$

ᄂ5. Slowly increase FG-5 to unit mark t50.

6. Let purge for 2 minutes.

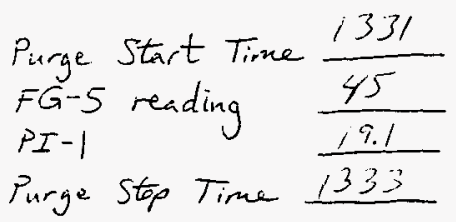

*Periodically check carbonldryrite cylinder for gross liquid contamination during tank gas purge. Shut down system should this occur.

6. 7. Close valves V-6 and V-7.

6. Turn off sample pump.

9. Reset Stopwatch Mó. Simultaneously: Open SUMMA canister valve Start Time 1335

11. Allow 60 seconds for canister to fill.

-12. Close the SUMMA" canister valve. Stop Time $133 \%$

-13. Clese valve V-5.

14. Remove the exposed SUMMA* canister and replace SUMMA" station cap or install next SUMM1A" sample and repeat procedure at step 2.

15. Record any anomalies in tield notes.

-16. Return to standhy inode (Section 8.2). 
WHC-SO-WM-OTR-196, REV. O

WHC-IP-1127, Sampling and Mobile Laboratories Procedures

Rev. 0

Vapor Sampling of Waste Tanks Using

May 5, 1995

In Situ Vapor Sampling System (ISVS)

Page 12 of 16

Bundle C

Canister 7229 SUMMA" CANISTER SAMPLING

Tank $\frac{5102}{263106}$

Date

Time 1335

1. From Stand-hy Mode, remove cap from the SUMMA* Sampling Station and connect the SUMMA" canister.

2. Open valve $\mathrm{V}-5$ and $\mathrm{V}-6$.

3. Start sample pump.

4. Open valve $V-7$

5. Slowly increase FG-5 to unit mark $\begin{array}{r}45 \\ 50\end{array}$

Pirge Start Tirne 1337 $F G-5$ reading $\frac{45}{19.0}$
$P I-1$

6. Let purge for 2 minutes.

Purge Stop Tire 1339

* Periodically check carbonldryrite cylinder for gross liquid contamination during tank gas purge. Shut down system should this occur.

7. Close valves $V-6$ and $v-7$.

$\checkmark$. Turn otf sample pump.

V. Reset Stopwatch

10. Simultaneously: Open SUMMA canister valve Start Time 1339 Start Stopwatch

11. Allow 60 seconds for canister to fill.

12. Close the SUMMA* canister valve. Stop Time 1340

13. Cluse villve V-5.

14. Remove the exposed SUMMA" canister and replace SUMMA" station cap or install next SUMMA" simple and repeat procedure at step 2.

15. Record any anomalies in tield notes.

16. Return to stianulby inude (Section 8.2). 
WHC-SD-WM-196, REV. 0

WHC-IP-1127, Sampling and Mobile Laboratories Procedures

4.8

Vapor Sampling of Waste Tanks Using

Rev. 0

In Situ Vapor Sampling System (ISVS)

May 5, 1995

Page 12 of 16

Bundle $C$

Tank $5-102$

APPENDIX IV

Canister 7230 SUMMA* CANISTER SAMPLING

Date $2 \in 5$ a N 96

Time 1339

ᄂ. From Stand-by Mode, remove cap from the SUMMA* Sampling Station and connect the SUMMA" canister.

2. Open value V-5 and V-6.

3. Start sample pump.

-4. Open valve V-7

5. Slowly increase FG-5 to unit mark t50.

6. Let purge for 2 ininutes.

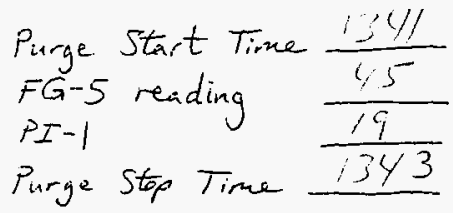

*Periodically check carbonidryrite cylinder for gross liquid contamination during tank gas purge.

Shut down system should this occur.

7. Close values V-6 and V-7.

8. Turn off sample pump.

9. Reset Stopwatch

10. Simultaneously: Open SUMMA canister valve Start Time 1343 Start Stopwatch

-11. Allow 60 seconds for canister to fill.

- 12. Close the SUMMA" canister valve.

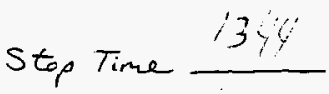

2 13. Cluse valve V-5.

- 14. Remove the exposed SUMMA" eanister and replace SUMMA" station cap or install next SUMMA" sample and repeat prucedure at step 2.

15. Record any anomalies in tield notes.

16. Return to standhy mode (Section 8.2). 
WHC-SD-WM-OTR-196. REV. 0

WHC-IP-1127, Sampling and Mobile Laboratories Procedures

Vapor Sampling of Waste Tanks Using

Rev. 0

In Situ Vapor Sampling System (ISVS)

May 5, 1995

Page 12 of 16

Bundlec

Camister 248 SUMMA- CANISTER SAMPLING

Tank $5-102$

Date 26 TAN 96

Time 1345

*1. From Stand-hy Mude, remove cap from the SUMMA* Sampling Station and connect the SUMMA" canister.

L. Open valve V-5 and V-6.

L. Start sample pump.

24. Open valve V-7

5. Slowly increase FG-5 to unit mark t50.

Pirge Start Tine $\frac{346}{45}$ FG-5 reading

$P I-1$

19

6. Let purge for 2 minutes.

Purge Stop Time $134 S$

*Periodically check carbonldryrite cylinder for gross liquid contamination during tank gas purge. Shut down system should this occur.

7. Close valves V-6 and V-7.

8́. Turn off sample puinp.

9. Reset Stopwatch

10. Simultaneously: Open SUMMA canister valve Start Time 10,3 Start Stopwatch

11. Allow 60 seconds for canister to till.

12. Close the SUMMA" canister valve.

Stop Time 1349

213. Cluse valve V-5.

14. Remove the exposed SUMMA" canister and replace SUMMA" station cap or install next SUMMA" sample and repeat procedure at step 2.

- 15. Record any anomalies in field notes.

16. Return to standby mode (Section 8.2). 


\section{APPENDIX II \\ SETTING SYSTEM FLOW RATES}

\section{FOE SUMMA" SAMPLING}

1.

From Stand-by Mode, open valve V-5, V-6.

2. Ensure valven $\mathrm{Y}-1, \mathrm{~V}-2, \mathrm{~V}-3$ and V-4 are closed.

3. Without SUMMA* line egnnected to sample port 5:

a. Turn on sample pump andopen valve V-7.

b. Adjust rotameter FG-5 to the desired thow range (usually the 150 mark).

c. Allow system to purge for the desirestime.

d. Close valve V-7, V-5 and V-6.

e. Turn OFF the sample pump.

4. Connect wire re-enforced retlon line in tube bundle to SUMMA sample port.

5. System is operational tor SUMMA" sampling.

\section{FOF SORBENT SAMPLING Bundle C PNLT/5TS}

$\checkmark$ 1. From Stand-hy Mode, open valves V-1, V-2, V-3, and V-4

2. Ensure valve V-6 is clnsed.

‥ W. With no sample lines connected to the sample ports:

a. Turn ON the sample pump.

-h. Open valve V-7

t. Op Op

d. With the rotameter needle valves (FG-1 through FG-4), adjust the flow rate, indicated by the Flowmeter, to the desired thow range. $3205 \mathrm{ccm}$

$\checkmark$ Ensure the totalizers are counting tlow volume.

$\checkmark f$ Cluse valve $V-1, V-2, V-3, V-4$ and $V-7$.

$\checkmark$ Turn OFF the sample pump.

4. System is operational for sorbent sampling. 


\section{APPENDIX III \\ SORBENT TUBE SAMPLING

1. From Stand-by Mode, ensure the cap is on the SUMMA" Sampling Station. Connect wire reenforced tefion line in tube bundle to SUMMA sample port.

2. Open valve V-5 and V-6.

3. Start sample pump.

4. Open valve V-7

5. Slowly increase FG-5 to unit mark +50 .

-6. Let purge for 2 minutes.

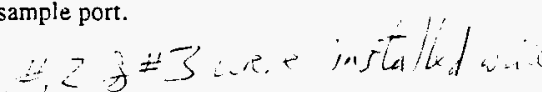

$$
\begin{aligned}
& \text { अalve } 1,2,3 \text {, }
\end{aligned}
$$

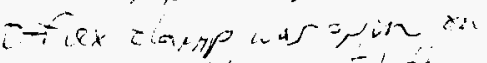

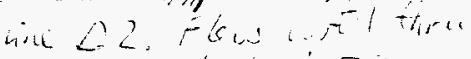

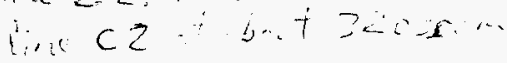

$$
\begin{aligned}
& \rightarrow, \cdots, \text { Lisic }
\end{aligned}
$$

*Periodically check carbonldryrite cylinder for gross liquid contamination during tank gas purge.

Shut down system should this occur.

7. Close valves $V-5, V-6$ and $V-7$.

8. Turn off sample pump.

9. Attach tube bundle sample lines to the sample ports 1 through 4.

-10. Second person independently verify correct connections. If any sample port is NOT in use, ensure the respective valve $(V-1$ through $V-4)$ is closes.

-11. On the tube bundle upstream of the sample ports, open C-tlex clamps on sample lines in use.

: 12. Start sample pump.

13. Zero tntalizers.

14. Open valve V.7.

15. Record time and open valves $v-1$ thru $v-4$ at 30 second intervals. Start Time

16. Verify all Flowmeters are indiciting the desired flow range. Adjust as necessary.

17. Verify Tualizers are counting tutal volume.

18. Verify sicila gel tuhes SG-1, SG-2, SG-3 and SG-4 show no liquid contamination.

*Periodically check silica gel fur gross liquid contamination during sorbent sampling. Shut down system should this occur. 
ᄂ15. At elapsed time, 2 minutes, enter into field notes;
a. Flow räte of each line measured at the corresponding Flowmeter.
b. Temperature of sampling system $\mathrm{T}-1, \mathrm{~T}-2, \mathrm{~T}-3$ and $\mathrm{T}-4$.
c. Internal vacuum indicated at $\mathrm{PI}-1$ in inches of $\mathrm{Hg}$.
d. Any field observations during sampling.

20. During sorbent tube collection enter into field notes;
a. Flow rate of each line measured at the corresponding Flowmeter.
h. Temperature of sampling system $\mathrm{T}-1$ and $\mathrm{T}-2$.
c. Internal vacuum indicated by $\mathrm{PI}-\mathrm{I}$ in inches of $\mathrm{Hg}$.
d. Any field observations during sampling.

21. When each totalizer has counted the desired volume-range specified in the TCP, close the

zla. hieit 5 mintes basie ciusing $=$-flex clamps and renowing sample lines (step 2y)

22. Close valve V-7 and shut off pump.

-23. Record sample volumes and actual sample time into field notes.

24. Close C-flex clamps and remove sample lines from sample ports.

25. Record any anomalies in field notes.

26. Return to standhy mode (Section 8.2).

$$
\begin{aligned}
& F T * 1 \frac{204}{F T * 2 \underline{260}} \\
& F T * 3205 \\
& F T \# 4
\end{aligned}
$$


WHC-SD-WM-OTR-196, REV. O

TANK $\frac{5-102}{26 J_{\text {AN } 96}}$
DATE $\frac{1358}{\text { TIME }}$

\begin{tabular}{|c|c|c|c|c|}
\hline Sample \# & Port \# & $\begin{array}{c}\text { Start } \\
\text { Time }\end{array}$ & $\begin{array}{c}\text { Stop } \\
\text { Time }\end{array}$ & $\begin{array}{l}\text { Totalizer } \\
\text { Volume }\end{array}$ \\
\hline 827 & 1 & 1359 & & 204 \\
\hline 828 & 2 & 1359 & & 260 \\
\hline 830 & 3 & 1359 & & 205 \\
\hline & 4 & & & \\
\hline
\end{tabular}

\begin{tabular}{|l|l|l|l|l|l|l|l|l|l|}
\hline TIME & FM-1 & FM-2 & FM-3 & FM-4 & T-1 & T-2 & T-3 & T-4 & PI-1 \\
\hline & & & & & & & & & \\
\hline & & & & & & & & & \\
\hline & & & & & & & & & \\
\hline & & & & & & & & & \\
\hline & & & & & & & & & \\
\hline & & & & & & & & & \\
\hline & & & & & & & & & \\
\hline & & & & & & & & & \\
\hline & & & & & & & & & \\
\hline & & & & & & & & & \\
\hline & & & & & & & & & \\
\hline & & & & & & & & & \\
\hline & & & & & & & & & \\
\hline
\end{tabular}




\section{APPENDIX II \\ SETTING SYSTEM FLOW RATES}

FQR: SUMMA" SAMPLING

1. Frong Stand-lyy Mode, open valve V-5, V-6.

2. Ensure valves $\mathrm{K}-1, \mathrm{~V}-2, \mathrm{~V}-3$ and $\mathrm{V}-4$ are closed.

3. Without SUMMA line cennected to sample port 5:

a. Turn on sample pump andegen valve $V-7$.

b. Adjust rotameter FG-5 to the dexired tlow range (usually the 150 mark).

c. Allow system to purge for the desired time.

d. Close value V-7, V-5 and V-6.

e. Turn OFF the sample pump.

4. Connect wire re-entorced teflon line in tube bundle to SUMMA sample port.

5. System is operational tor SUMMA" sampling.

\section{FOR SORBENT SAMPLING Bundle C PNE TSTS}

Flow 1. From Stand-by Mode, open valves V-1, V-2, V-3, and V-4

alredy adiusted

2. Ensure valve $V-6$ is closed.

from. previous

3. With no sample lines connected to the sample ports:

sists

d. Turn ON the sample pump.

b. Open value $V .7$

1. Ol

d. With the rotameter needle valves (FG-1 through FG-4), adjust the flow rate, indicated by the Fowmeter, to the desired tlow range. $3205 \mathrm{ccm}$

e. Ensure the totalizers are counting tlow volume.

t. Close valve $V-1, V-2, V-3, V-4$ and $V-7$.

g. Turn OFF the sample pump.

4. System is operational for sorbent sampling. 


\section{APPENDIX III}

\section{SORBENT TUBE SAMPLING}

1. From Stand-by Mode, ensure the cap is on the SUMMA" Sampling Station. Connect wire reenforced tefion line in tube bundle to SUMMA" sample port.

1. Open valve $V-5$ and $V-6$.

1. 3. Start sample pump.

4. Open valve V-7

5. Slowly increase FG-5 to unit mark +50.

\llcorner

6. Let purge for 2 minutes.

*Periodically check carhonldryrite cylinder for gross liquid contamination during tank gas purge. Shut down system should this occur.

7. Close valves V-5, V-6 and V-7.

8. Turn off sample pump.

9. Attach tube bundle sample lines to the sample ports 1 through 4.

10. Second person independently verify correct connections. If any sample port is NOT in use, ensure the respective valve ( $V-1$ through $V-4$ ) is closed.

11. On the tube bundle upstream of the sample ports, open C-tlex clamps or sample lines in use.

12. Start sample pump.

13. Zero totalizers.

- 14. Open Valve V-7.

15. Record time and open valves $V_{-1}$ thru $V_{-4}$ at 30 second intervals. Start Time $1 / 06$

16. Verify all Flowmeters are indicating the desired flow range. Adjust as necessary.

$\checkmark$ 17. Verity Totalizers are counting totil volume.

18. Verity sicila gel tuhes SG-1, SG-2, SG-3 and SG-4 show no liquid contamination.

* Periodically check silica gel for gross liquid contamination during sorbent sampling. Shut down system should this occur. 
WHC.SD.WM-OTR-196, REV.O

WHC-IP-1127, Sampling and Mobile Laboratories Procedures

Vapor Sampling of Waste Tanks Using

19. At elapsed time, 2 minutes, enter into field notes;

a. Flow rate of each line measured at the corresponding Flowmeter.

b. Temperature of sampling system $T-1, T-2, T-3$ and $T-4$.

c. Internal vacuum indicated at PI-1 in inches of $\mathrm{Hg}$.

d. Any field observations during sampling.

20. During sorbent tube collection enter into field notes;

a. Flow rate of each line measured at the corresponding Flowmeter.

b. Temperature of sampling system T-1 and T-2.

c. Internal vacuum indicated by PI-1 in inches of $\mathrm{Hg}$.

d. Any field observations during sampling.

ᄂ21. When each totalizer has counted the desired volume-range specified in the TCP, close the appropriate valve $\mathrm{V}-1$ through $\mathrm{V}-4$.

21a. Wait 5 mintes besie ciosing e-flex clamps and remowing sample lines (step 2y)

22. Close valve $V-7$ and shut off pump.

23. Record sample volumes and actual sample time into tield notes.

-24. Close C-flex clamps and remove sample lines from sample ports.

25. Record any anomalies in field notes.

L 26. Return to standhy mode (Section 8.2).

$$
\begin{aligned}
& F T=1 \frac{209}{F T * 2 \leq 207} \\
& F T * 3 \leq 204 \\
& F T * 4
\end{aligned}
$$




\begin{tabular}{|c|c|c|c|c|}
\hline Sarnple \# & Port \# & $\begin{array}{c}\text { Start } \\
\text { Time }\end{array}$ & $\begin{array}{c}\text { Stop } \\
\text { Time }\end{array}$ & $\begin{array}{l}\text { Totalizer } \\
\text { Volume }\end{array}$ \\
\hline 831 & 1 & 1406 & & 209 \\
\hline 832 & 2 & 1406 & & 207 \\
\hline 833 & 3 & 1426 & & 204 \\
\hline & 4 & & & \\
\hline
\end{tabular}

\begin{tabular}{|l|l|l|l|l|l|l|l|l|l|}
\hline TIME & FM-1 & FM-2 & FM-3 & FM-4 & T-1 & T-2 & T-3 & T-4 & PI-1 \\
\hline & & & & & & & & & \\
\hline & & & & & & & & & \\
\hline & & & & & & & & & \\
\hline & & & & & & & & & \\
\hline & & & & & & & & & \\
\hline & & & & & & & & & \\
\hline & & & & & & & & & \\
\hline & & & & & & & & & \\
\hline & & & & & & & & & \\
\hline & & & & & & & & & \\
\hline & & & & & & & & & \\
\hline & & & & & & & & & \\
\hline & & & & & & & & & \\
\hline
\end{tabular}




\section{APPENDIX Il \\ SETTING SYSTEM FLOW RATES}

\section{FOR SUMMA" SAMPLING}

1. Frow Stand-ling Mode, open valve V-5, V-6.

2. Ensure valves V-1, V-2, V-3 and V-4 are closed.

3. Without SUMMA' lineconnected to sample port 5:

a. Turn on sample pump andonen valve V-7. 45

b. Adjust rotameter FG-5 to the sirirel tow range (usually the +50 mark).

c. Allow system to purge for the destred time.

d. Close valve V-7, V-5 and V-6.

e. Turn OFF the sample pump.

4. Connect wire re-entorced tetlon line in tube bundle to SUMAN sample port.

5. System is operational for SUMMA" sampling.

\section{FOR SORBENT SAMPLING $B_{\text {inn }} d / e \mathrm{C} \quad \mathrm{NH} / 3 / \mathrm{H}_{2} \mathrm{O}$}

1. From Stand-hy Mode, open valves V-1, V-2, V-3, and V-4

2. Ensure valve V-6 is closed.

3. With no sample lines connected to the sample ports:

Turn ON the sample pump.

b. Open valve V-7

I. IVith the rotameter needle valves (FG-1 through $F G-4$ ), adjust the tlow rate, indicated

$\checkmark$ by the Flowneter, to the desired tlow range. 220

Ensure the totalizers are counting flow volume.

f. Cluse valve V-1, V-2, V-3, V-4 and V-7.

S. Turn OFF the sample pump.

4. System is uperational for sorbent sampling. 
WHC-SO-WM-OTR-196, REV. O

WHC-IP-1127, Sampling and Mobile Loboratories Procedures

\section{APPENDIX III \\ SORBENT TUBE SAMPLING}

Bundle $\mathrm{C} \quad \mathrm{NH}_{3} / \mathrm{H}_{2} \mathrm{O}$

2. From Stand-by Mode, ensure the cap is on the SUMMA Sampling Station. Connect wire reenforced teflon line in tube bundle to SUMMA" sample port.

-2 . Open valve $V-5$ and $V-6$.

3. Start sample pump.

4. Open valve V-7

5. Slowly increase FG-5 to unit mark +50.

2.6. Let purge for 2 minutes.

*Periodically check carbonldryrite cylinder for gross liquid contamination during tank gas purge. Shut down system should this occur.

7 . Close valves $V-5, V-6$ and $V-7$

$:$ ' Turn off sample pump.

9. Attach tube bundle sample lines to the sample ports 1 through 4.

'10. Second person independently verify correct connections. If any sample port is NOT in use, ensure the respective valve ( $\mathrm{V}-1$ through $\mathrm{V}-4)$ is closed.

11. On the tube bundle upstream of the sample ports, open C-tlex clamps on sample lines in use.

- 12. Start sample pump.

2. 13. Zero totalizers.

14. Open Valve V-7.

- 15. Record time and open valves $V-1$ thru $V-4$ at 30 second intervais. Start Time. $4 / 6$

16. Verify all Flowmeters are indicating the desired thow range. Adjust as necessary. $\checkmark$

17. Verity Totalizers are counting total volume.

L'18. Verify sicili gel tuhes SG-1, SG-2. SG-3 and SG-4 show no liquid contamination.

* Periodically check silica gel for gross liquid contamination during sorhent sampling. Shut down system should this occur. 
19. At elapsed time, 2 minutes, enter into field notes;

a. Flow rajte of each line measured at the corresponding Flowmeter.

b. Temperature of sampling system $T-1, T-2, T-3$ and $T-4$.

c. Internal vacuum indicated at PI-1 in inches of $\mathrm{Hg}$.

d. Any field observations during sampling.

$\sqrt{20}$. During sorbent tube collection enter into field notes;

a. Flow rate of each line measured at the corresponding Flowmeter.

b. Temperature of sampling system $\mathrm{T}-1$ and $\mathrm{T}-2$.

c. Internal vacuum indicated by $\mathrm{PI}-1$ in inches of $\mathrm{Hg}$.

d. Any field observations during sampling.

21. When each totalizer has counted the desired volume-tange specified in the TCP, close the

2la. Wait 5 minutes berie closing $=-$ flex clamps and rencring sample lines (step 24) $\checkmark 22$. Close valve $V-7$ and shut off pump.

23. Record sample volumes and actual sample time into field notes.

i. 24. Close C-tlex clamps and remove sample lines from sample ports.

25. Record any anomalies in field notes.

26. Return to standby mode (Section 8.2).

$$
\begin{aligned}
& F T \# 1,2002 \\
& F T * 2 \underline{2001} \\
& F T * 3,2001 \\
& F T * 4
\end{aligned}
$$


WHC-SD-WM-OTR-196, REV. O

TANK $5-102$

DATE 26519 N96

TIME 1415

\begin{tabular}{|c|c|c|c|c|}
\hline Sample \# & Port \# & $\begin{array}{l}\text { Start } \\
\text { Time }\end{array}$ & $\begin{array}{c}\text { Stop } \\
\text { Time }\end{array}$ & $\begin{array}{c}\text { Totalizer } \\
\text { Volume }\end{array}$ \\
\hline 885 & 1 & 1416 & & 2002 \\
\hline 895 & 2 & 141630 & & 2001 \\
\hline 905 & 3 & 1417 & & 2001 \\
\hline & 4 & & & \\
\hline
\end{tabular}

\begin{tabular}{|c|c|c|c|c|c|c|c|c|c|}
\hline TJME & $F M-1$ & $F M-2$ & $F M-3$ & $F M-4$ & $T-1$ & $T-2$ & $T-3$ & $T-4$ & PI-1 \\
\hline $2 !$ & 2,1 & 221 & $2 Z 1$ & 1 & $-Z, \epsilon$ & 23,6 & 27 & -2 & 2.2 \\
\hline & & & & & & & & & \\
\hline & & & & & & & & & \\
\hline & & & & & & & & & \\
\hline & & & & & & & & & \\
\hline & & & & & & & & & \\
\hline & & & & & & & & & \\
\hline & & & & & & & & & \\
\hline & & & & & & & & & \\
\hline & & & & & & & & & \\
\hline & & & & & & & & & \\
\hline & & & & & & & & & \\
\hline & & & & & & & & & \\
\hline & & & & & & & & & \\
\hline
\end{tabular}




\section{APPENDIX II \\ SETTING SYSTEM FLOW RATES}

\section{FQF SUMMA" SAMPLING}

1. From Stand-by Mode, open valve V-5, V-6.

2. Ensure valves $\mathrm{Y}-1, \mathrm{~V}-2, \mathrm{~V}-3$ and V-4 are closed.

3. Without SUMMA* line sannected to sample port 5:
a. Turn on sample pump and genen valve V-7.

b. Adjust rotameter FG-5 to the decired flow range (usually the 150 mark).

c. Allow system to purge for the desiredime.

d. Close value V-7, V-5 and V-6.

e. Turn OFF the sample pump.

4. Connect wire re-entorced teflon line in tube bundle to SUMMA

5. System is operational for SUMMA" sampling.

\section{FOR SORBENT SAMPLING Bundle $\mathrm{NH}_{3} / \mathrm{H}_{2} \mathrm{O}$}

1. From Stand-hy Mode, open valves $V-1, V-2, V-3$, and V-4

2. Ensure valve $V-6$ is closed.

3. With no sample lines connected to the sample ports:

Turn ON the sample pump.

h. Open valve $V-7$

2. O-OW

W. With the rotameter needle valves (FG-1 through FG-4), adjust the flow rate, indicated by the Fluwmeter, to the desired flow range.

$\checkmark$ Ensure the totalizers are counting flow volume.

$v f$ Cluse valve $V-1, v-2, V-3, v-4$ and $V-7$.

$\checkmark$ Turn OFF the sample pump.

4. System is operational for sorbent sampling- 


\section{APPENDIX III Bundle C NH3/ $/ \mathrm{H}_{2} \mathrm{O}$ SORBENT TUBE SAMPLING}

$\checkmark i$. From Stand-by Mode, ensure the cap is on the SUMMA" Sampling Station. Connect wire reenforced tefion line in tube bundle to SUMMA" sample port.

2. Open valve V-5 and V-6.

2. Start sample pump.

4. Open valve V-7

- 5. Slowly increase FG-5 to unit mark +50.

6. Let purge for 2 minutes.

*Periodically check carbonldryrite cylinder for gross liquid contamination during tanḳ gas purge. Shut down system should this occur.

ᄂ. Close valves $V-5, V-6$ and $V-7$.

18. Turn off sample pump.

i 9. Attach tube bundle sample lines to the sample ports 1 through 4.

10. Second person independently verify currect connections. If any sample port is NOT in use, ensure the respective valve ( $\mathrm{V}-1$ through $\mathrm{V}-4$ ) is closed.

11. On the tube bundle upstream of the sample ports, open C-tlex clamps on sample lines in use.

12. Start sample pump.

13. Zero totalizers.

14. Open Valve V-7.

15. Record time and open valves $V-I$ thru $V-4$ at 30 second intervals. Start Time

16. Verify all Flowmeters are indicating the desired tlow range. Adjust as necessary.

:17. Verify Totalizels are counting total volume.

18. Verify sicila get tubes SG-1, SG-2, SG-3 and SG-4 show no liquid contamination.

*Periouically check silica gel tor gross liquid contamination during sorbent sampling. Shut down system should this occur. 
19. At elapsed time, 2 minutes, enter into field notes;

a. Flow ràte of each line measured at the corresponding Flowmeter.

b. Temperature of sampling system $T-1, T-2, T-3$ and $T-4$.

c. Internal vacuum indicated at $\mathrm{PI}-1$ in inches of $\mathrm{Hg}$.

d. Any field observations during sampling.

20. During sorbent tube collection enter into field notes;
a. Flow rate of each line measured at the corresponding Flowmeter.
b. Temperature of sampling system T-1 and T-2.
c. Internal vacuum indicated by $\mathrm{PI}-1$ in inches of $\mathrm{Hg}$.
d. Any field observations during sampling.

$\checkmark 21$. When each totalizer has counted the desired volume-range specified in the TCP, close the 'Zla. Wait 5 minntes befie closing $=$-flex clamps and remasing jample lines (step 24) $\sqrt{ } 22$. Close valve $V-7$ and shut off pump.

$\checkmark 23$. Record sample volumes and actual sample time into field notes.

24. Close C-flex clamps and remove sample lines from sample ports.

25. Record any anomalies in field notes.

26. Return to standby mode (Section 8.2).

$$
\begin{aligned}
& F T \# 1 \frac{2000}{2002} \\
& F T \# 2 \frac{2001997}{F T \# 4=2001}
\end{aligned}
$$


WHC-SDWM-OTR-196, REV. O

TANK $5+102$

DATE $26 J_{A N^{\prime}} 96$

TIME 1433

\begin{tabular}{|r|c|c|c|c|}
\hline Sample \# & Port \# & $\begin{array}{c}\text { Start } \\
\text { Time }\end{array}$ & $\begin{array}{c}\text { Stop } \\
\text { Time }\end{array}$ & $\begin{array}{c}\text { Totalizer } \\
\text { Volume }\end{array}$ \\
\hline 915 & 1 & 1434 & & 2000 \\
\hline $92 S$ & 2 & 143430 & & 2002 \\
\hline 935 & 3 & 1435 & & 1997 \\
\hline$U 1,14, T 1$ & 4 & 143530 & & 2001 \\
\hline
\end{tabular}

\begin{tabular}{|c|c|c|c|c|c|c|c|c|c|}
\hline TIME & $F M-1$ & $F M-2$ & $F M-3$ & $F M-4$ & $T-1$ & $T-2$ & $T-3$ & $T-4$ & $P I-1$ \\
\hline 1437 & 216 & 217 & 218 & 215 & $-5,3$ & 24 & 27 & -1 & 19.5 \\
\hline 1441 & 219 & $22 /$ & 221 & 216 & & & & & \\
\hline & & & & & & & & & \\
\hline & & & & & & & & & \\
\hline & & & & & & & & & \\
\hline & & & & & & & & & \\
\hline & & & & & & & & & \\
\hline & & & & & & & & & \\
\hline & & & & & & & & & \\
\hline & & & & & & & & & \\
\hline & & & & & & & & & \\
\hline & & & & & & & & & \\
\hline & & & & & & & & & \\
\hline & & & & & & & & & \\
\hline
\end{tabular}


3. Monitor the placement of the tube bundle in the containment structure.

4. Monitor the tube bundle during insertion to ensure Operations placement at the correct depth/location, per TCP instructions.

5. In the field notes, record the;

- Depth and location

- LEL measurement

- OVM reading

- Ammonia concentration measured by colorimetric tubes

- Any anomalies associated with setup.

\subsection{Standby Mode}

1. During the standby mode the sample cart shall be ready for operation and in the following configuration:
a. Tube bundle is in the sampling position/location in the tank but not connected to the cart.
b. Valves V-1, V-2, V-3, V-4, V-5, V-6 and V-7 are closed.
c. Sample pump is off.
d. Fuwer is on to the flowmeters and totallizers

2. The standby mode serves as a reference point from which the following functions can be performed.

\begin{tabular}{||l|c|}
\hline \multicolumn{1}{|c|}{ Description } & Appendix \\
\hline Leak Test & I \\
\hline Selting System Flow Rates & II \\
\hline Sorbent Tube Sampling & III \\
\hline SCMMA" Canister Sampling & IV \\
\hline Flow-Through Cylinder Sampling & V \\
\hline
\end{tabular}

\subsection{Shutdown}

1. Request HPT coverage during steps 2 through 6.

2. Monitor Operations removal of the tube bundle frum the tank.

3. Receive tube bundle and move to low hackground area.

$\sqrt{4}$. Dismantle tube hundle and bag sorhents for shipment to lahoratory. 
5. Collect WA4 filters from the sample head.

$V_{3} . \quad-\quad$-Request HPT survey of filters for sample release.

6. Place upstream HEPA filter in labeled petri dish for submittal to 222-S.

c. Place downstream filter in labeled petri dish for submittal to 222-S.

$\sqrt{6 .}$ Remove ISVS from Tank Farm. -Joved drys fler sapphing event

\subsection{RECORDS}

All documents generated from sampling activities will be reviewed and evaluated as quality records in accordance with WHC-CM-3-5, Document Control and Records Management Manual. Copies of all field generated infotmation will be forwarded to the Tank Farms project manager or cognizant engineer. Original documents will be handled as directed in the appropriate regulation. The following documentation may be recjuired.

- Controlled field loghook (to include)

- Sample I.D. data

- Raw data (that is, pressure, temperature, tlow rate, time, and so forth).

- Shipping documentation

- Onsite Routine Radioactive Shipment Record, form A-6000-528.

- Oft-Site Property Control, form 54-3000-479.

- Off-Site Radioactive Shipment Record, form 54-6000-088.

- Radionuclides analysis from 222-S Laboratory.

- COC documentation.

- Request for Special Analysis, form BC-6700-181.

- Photograph(s) taken cluring the sampling activity.

\subsection{REFERENCE}

WHC-CM-3-5, Document Commol and Records Manugement Manual. 


\section{APPENDIX $V$ \\ FLOW-THROUGH CYLINDER SAMPLING}

$$
\text { Not used }
$$

1. From Stand-by Mode, ensure valve V-5 is closed.

2. Remove be Cllex tube from the downstream side of the SUMMA" sample station.

3. Connect the ypstream side of the flow-through sample cylinder to the downstream side of the SUMMA" statiog (be sure to orient proper direction-of-tlow arrows on tlow-through cylinder valves).

4. On the down-stream side of the flow-through sample cylinder connect the upstream side of C-flex tubing to the pump.

5. Turn on sample pump.

6. Open valve $\mathrm{V}-6$ and $\mathrm{V}-7$.

7. Open upstream valve on the tlow-through cylinder.

8. Open downstream valve on the flow-through cylinder.

9. Simultaneously: Open valve V-5 Start Stopwatch

*Periodically check carbonldryrite cylinder for gross łiquid contamination during tank gas purge. Shut down system should this occur.

10. If needed, perform slight adjustment to rotameter FG-5 to the appropriate unit mark.

11. Record rotameter FG-5 reading.

12. Purge tank vapor through the cylinder for appropriate time as specified in the TCP.

13. After the specified purge time simultaneously: Close downstrean flow-through cylinder valve

14. Close upstream flow-through cylinder valve Stop Stopwatch

15. Close valve $V-5, V-6$, and $V-7$.

16. Turn off sample pumpl).

17. Remove tlow-through cylinder.

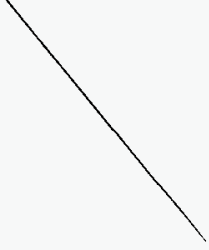


WHC-II'-1 27, Sampling and Mobile Laboratories Procedures

Vapor Sampling of Waste Tanks Using May 5, 1995

In Situ Vapor Sampling System (ISVS)

Page 14 of 16

18. Re-connect C-tlex to downstream side of SUMMA" station

19. Record any anomalies in field notes

20. Return to standby mode (Section \&2). 

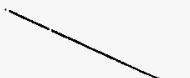

更

\section{APPENDIX VI PITOT TUBE SAMPLING}

Sampling by pitot tubecan be performed if the waste tank is equipped with a ventilation port that accesses the vapor or head space in the tank. A fitting must be designed to reduce the ventilation port to accommodate a $1 / 4$ inch phot tube for sampling operations. The pitot tube should extend 6 inches or half way into the duct and approximately three inches outside the duct. The tube bundle is attached directly to the end of the exposed pitot tube on the outside of the duct.

1. The appropriate site personnel will install the pitot tube in the designated access as directed by the cognizant engineer.

2. The pitot tube will be $1 / 4$ inch stainless steel secured with Swagelok and or NPT fittings.

3. The sample head is equipned with an adapter which allows it to attach directly to the $1 / 4$ inch pitot tube. The tube bundle should he secured in an upright position.

4. Return to Section 8.1.1. 


$$
\text { WHC-SO-WM-OTR-196, REV. O }
$$

WHC-IP-1127, Sampling and Mobile Laboratories Procedures

4.8

Rev. 0

Vapor Sampling of Waste Tanks Using

In Situ Vapor Sampling System (ISVS)

May 5, 1995

Page 16 of 16

APPROVAL

Approval Designator: SQ

Author: R. L. Ragan, Sampling and Mobile Laboratories

Approved by: $\quad$ D. L. Edwards, Manager

Sampling and Mobile Laboratories

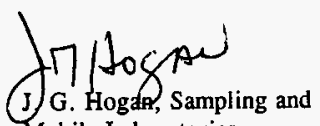

Mobile Laboratories

Approved by: R. L. Ragas, Sampling and Mobile Laboratories

Approved by:

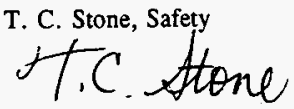

Approved by:

C. J. Stephan, Environmental Quality Assurance
Date $5 / 2 / 95$

Date $5 / 2 / 95$

Date $5 / 1 / 95$

Date $\frac{4}{3 / 36 / 9195}$

Date $4 / 27 / 95$

Date $4 / 25 / 95$

A-73 